TI 2017-070/VI

Tinbergen Institute Discussion Paper

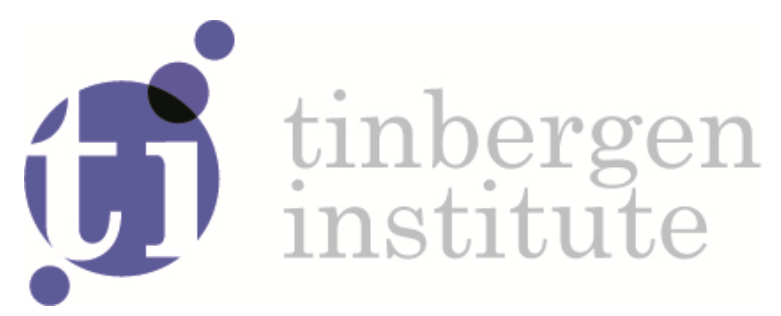

\title{
Should Pollution Taxes Be Targeted At Income Redistribution?
}

Bas (B.) Jacobs ${ }^{1}$

Rick (F.) van der Ploeg ${ }^{2}$

1: Erasmus University Rotterdam, Tinbergen Institute and CESifo; Tinbergen Institute, The Netherlands

2: University of Oxford, Tinbergen Institute, CEPR and CESifo 
Tinbergen Institute is the graduate school and research institute in economics of Erasmus University Rotterdam, the University of Amsterdam and VU University Amsterdam.

Contact: discussionpapers@tinbergen.nl

More TI discussion papers can be downloaded at the Tinbergen Site

Tinbergen Institute has two locations:

Tinbergen Institute Amsterdam

Gustav Mahlerplein 117

1082 MS Amsterdam

The Netherlands

Tel.: +31(0)20 5984580

Tinbergen Institute Rotterdam

Burg. Oudlaan 50

3062 PA Rotterdam

The Netherlands

Tel.: +31(0)10408 8900 


\title{
SHOULD POLLUTION TAXES BE TARGETED AT INCOME REDISTRIBUTION?*
}

\author{
Bas Jacobs \\ Erasmus University Rotterdam, Tinbergen Institute and CESifo** \\ Frederick van der Ploeg \\ University of Oxford, Tinbergen Institute, CEPR and CESifo***
}

July, 2017

\begin{abstract}
This paper analyses optimal corrective taxation and optimal income redistribution. Under general utility functions, the Pigouvian pollution tax is higher if pollution damages disproportionally hurt the poor due to equity weighting of pollution damages. Moreover, optimal pollution taxes should be set below the Pigouvian tax if the poor spend a disproportionate fraction of their income on polluting goods. However, if preferences for commodities are of the Gorman (1961) polar form, optimal pollution taxes should follow the first-best rule for the Pigouvian corrective tax even if the government wants to redistribute income and the poor spend a disproportional part of their income on polluting goods. The often-used quasi-linear, CES and Stone-Geary utility functions all belong to the Gorman polar class. If preferences are Gorman polar, and if pollution taxes are not optimized, Pareto-improving green tax reforms exist that move the pollution tax closer to the Pigouvian tax. Simulations demonstrate that optimal corrective taxes should be Pigouvian if the demand for polluting goods is derived from a LES demand system, but deviate from the Pigouvian taxes if demand for polluting goods demand is derived from a PIGLOG demand system.
\end{abstract}

Keywords: redistributive taxation, corrective pollution taxation, Gorman polar form, Stone-Geary JEL codes: $\quad$ H21, H23, Q54

\footnotetext{
* We thank Florens Flues for sharing OECD data and Diane Aubert, Lans Bovenberg, Sybren Cnossen, Moritz Drupp, David Klenert, Linus Mattauch, Gerard van der Meijden, Ian Parry, and Erik Verhoef for helpful comments. We are grateful to the helpful comments of participants at the Workshop on Climate Change and Distribution, organised by ESOP and Centre for the Study of Mind in Nature in collaboration with the Stanford Center for Ethics in Society, Oslo, June 2010, the EAERE Conference, Prague, 2012 and Athens, 2017, and various seminars. We acknowledge support from the ERC Advanced Grant 'Political Economy of Green Paradoxes' (FP7-IDEAS-ERC Grant No. 269788).

** Address: Erasmus School of Economics, Erasmus University Rotterdam, PO Box 1738, 3000 DR Rotterdam, The Netherlands. Phone: +31-10-4081452/41. E-mail: bjacobs@ese.eur.nl. Homepage: https://personal.eur.nl/bjacobs.

*** Also affiliated with St. Petersburg State University, 7/9 Universitetskaya nab., St. Petersburg, 1990034, Russia and VU University Amsterdam. Address: OxCarre, Department of Economics, Manor Road Building, Oxford OX1 3UQ, United Kingdom. Phone: +44-1865-281285. E-mail: rick.vanderploeg@economics.ox.ac.uk. Homepage: https://www.economics.ox.ac.uk/members/rick.vanderploeg.
} 


\section{Introduction}

Is a green policy to tax pollution externalities also a left policy in terms of income redistribution? Pollution taxes hurt the poor more than the rich, since the poor consume relatively more polluting goods than the rich. Figure 1 shows that the incidence of taxes on fuels and electricity falls more on the poor than on the rich, but taxes on transport fuels vary non-linearly with disposable income for an average of 21 OECD countries (Flues and Thomas, 2015). In the United Kingdom, outlays on energy are the biggest expenditure item after food for the poorest 10 percent of households, whereas energy is the smallest expense for the richest 10 percent (Advani et al., 2013). The regressivity of the United States' climate policy has been documented by Burtraw et al. (2009), Rausch et al. (2011), Hassett et al. (2011), and Fullerton et al. (2012). ${ }^{1}$ West and Williams III (2004) estimate an AIDS demand system for the United States for gasoline, leisure, and other goods. They show that the gasoline tax is regressive and argue that cuts in the labour tax can make climate policy less regressive, whilst lump-sum transfers can make it more progressive. Crainger and Kohlstad (2010) find that carbon permits or taxes in the United States are regressive, both from a current and from a lifetime income perspective. ${ }^{2}$ Moreover, a carbon tax of $\$ 15 / \mathrm{tCO} 2$ can be designed so that the adverse distributional incidence is limited to about 1 percent of annual income across all income quintiles, if \$29 billion out of \$79 billion revenue would be used to finance a cut in taxes for the first four income quintiles. Careful recycling of part of pollution tax revenue can thus offset the regressive effects of a pollution tax. ${ }^{3}$ However, India's coal tax might be mildly progressive as long as the poor do not have complete access to the power grid (Parry et al., 2017). On a global level, the incidence of pollution taxes might also be progressive, rather than regressive. For example, Chancel and Piketty (2015) find that the top-10 percent of carbon emittors in the world cause 45 percent of global emissions, while the bottom-50 percent emits only 13 percent. ${ }^{4}$ Therefore, they propose a global, progressive carbon tax, which would disproportionally fall on the rich.

Not only the incidence of pollution taxes, but also the incidence of pollution damages varies with income. For example, at the local level, poor people and especially their children suffer from fine-

\footnotetext{
${ }^{1}$ Pizer and Sexton (2017) survey the literature on the incidence of pollution taxes and household surveys for Mexico, the United States and the United Kingdom. They argue that the distributional impact depends on patterns in energy demand, the physical, social and climatic characteristics of the tax jurisdictions, and how the revenue is used. Variations of the incidence of pollution taxes across households within an income group may thus also be important.

${ }^{2}$ Both theory and empirics suggest that efficiency standards are less regressive than gasoline taxes (Levison, 2016).

${ }^{3}$ Fullerton and Monti (2013) analyse pollution taxes and distribution between unskilled and skilled workers in a general-equilibrium model with endogenous wages. They show that a pollution tax makes both groups worse off. In their calibration, the income loss of the unskilled workers is so large that recycling all revenue from the pollution tax only to them is not sufficient to compensate them.

${ }^{4}$ The idea is that anyone emitting, for example, more than $6.2 \mathrm{tCO} 2$ per year should pay a proportional carbon tax on carbon emissions above a tax-exempt threshold. According to Chancel and Piketty (2015), the revenues of this global carbon tax should finance an annual stream of 150 billion Euros to fund climate-adaptation programmes.
} 
particles pollution as they live and go to schools closer to busy roads and further away from parks (e.g., Miranda et al., 2011). At a global level, poor countries are hurt more by climate change than rich countries as they suffer more from desertification of their lands, extreme weather events and floods, as highlighted in the Stern Review (Stern, 2007). The poorer counties in the South also suffer more from the risk of global warming in terms of falling crop yields, labour productivity, rising mortality, and crime than the richer counties in the North of the United States (Hsiang et al., 2017). Furthermore, 20 of the 36 highest carbon-emitting countries are among the least vulnerable to negative impacts of future climate change, whilst 11 of the 17 countries with low or moderate emissions are acutely vulnerable to negative impacts of climate change (Althor et al., 2016). On the other hand, traffic congestion hurts the rich more than the poor, since their opportunity cost of time is higher (De Palma and Lindsey, 2004).

\section{Figure 1 - Energy taxes by net income, average of 21 OECD countries}

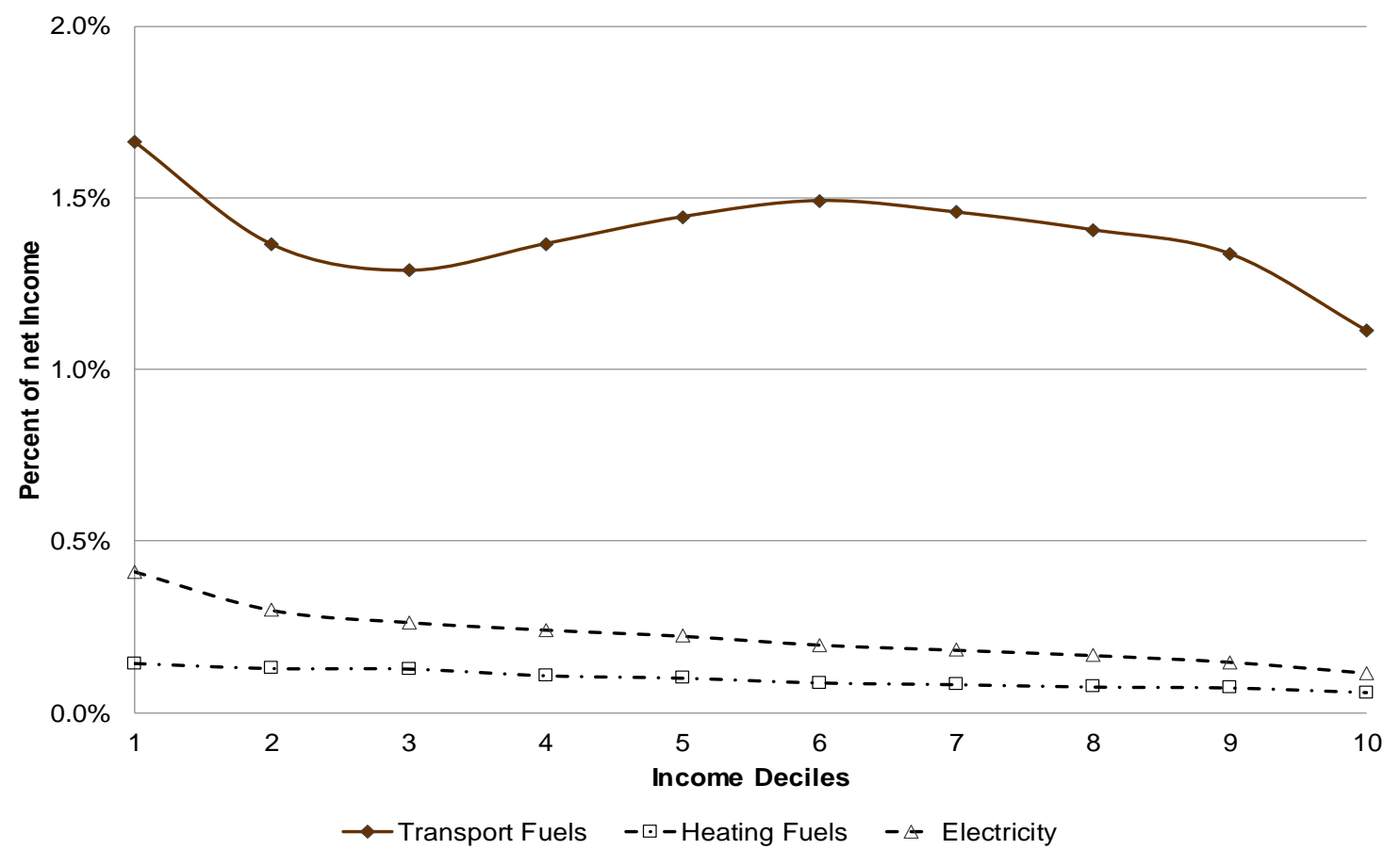

Source: Flues and Thomas (2015)

The main question of this paper is therefore: if the government can optimize income redistribution via linear income taxes, should the optimal setting of corrective take into account the distributional incidence of pollution taxes and the distributional incidence of pollution damages? Moreover, can green tax reforms be designed in such a way that revenues from pollution taxes can be recycled through the income tax to offset adverse distributional consequences of pollution taxes for the poor? To answer these questions, we employ and develop a standard model of optimal linear income taxation extended with linear corrective 
taxes on polluting goods. Individuals are heterogeneous in their earnings per hour worked and by how much they suffer from pollution damages. The government cares about income redistribution and efficiency, but also aims to internalise the damages from pollution that differ across income groups. Our paper has five contributions.

First, if preferences of households are unrestricted, we show that pollution taxes serve three goals: internalising externalities, redistributing income, and alleviating labour market distortions arising from redistributive income taxes. Naturally, pollution taxes are present to internalise pollution externalities. Distributional concerns affect the Pigouvian tax in two ways. On the one hand, as public resources are more valuable in societies with more inequality, the monetary value of environmental quality is lower if inequality is larger. Consequently, the government wishes to sacrifice environmental quality for public revenue (Aigner, 2014). On the other hand, distributional concerns affect the optimal Pigouvian tax via the weighting of pollution externalities with social welfare weights, or 'equity weights' (cf. Mirrlees, 1978; Anthoff et al., 2009; Anthoff and Tol, 2010). If the poor are hurt relatively more by pollution, and society cares about inequality, the Pigouvian tax should generally be set higher to avoid excessively adverse effects of pollution on lower incomes.

Second, with general preferences for clean and polluting commodities, the government typically wants to deviate from setting pollution taxes at Pigouvian rates for distributional reasons. If pollution taxes are regressive, in the sense that their incidence falls disproportionally on the lower incomes, they cause distributional losses and optimal pollution taxes should be set below the Pigouvian tax - ceteris paribus. ${ }^{5}$ Consequently, the government sacrifices on its environmental priorities to redistribute more income: 'Erst kommt das Fressen, dann die Moral' as in Bertold Brecht's The Threepenny Opera. Moreover, pollution taxes can also be driven below Pigouvian rates for efficiency reasons, since they generally raise the marginal tax wedge on labour, and thus exacerbate labour market distortions caused by the labour income tax, as is known from the literature on the double dividend (e.g., Sandmo, 1975; Bovenberg and De Mooij, 1994; Bovenberg and van der Ploeg, 1994).

Third, we show that, if preferences are weakly separable in goods and labour and belong to the Gorman (1961) polar form, the optimal pollution tax is set at the first-best rule, i.e., at the Pigouvian tax, even in second-best settings with distributional concerns, heterogeneous environmental damages and distortionary taxation. ${ }^{6}$ The first-best rule for the optimal pollution tax is, however, evaluated at the

\footnotetext{
${ }^{5}$ Baumgärtner et al. (2017) show that adjustments for the willingness to pay for environmental goods is substantially affected by income inequality. Adler et al. (2016) examine how priority for the poor affects the social cost of carbon.

${ }^{6}$ Williams III (2006) estimates an AIDS demand system for the U.S., which is not of the Gorman polar form. He finds that the optimal gasoline tax exceeds marginal social damages, though distributional concerns cause this tax rate to be substantially less than in a representative-agent model. Cremer et al. (2003) study the incidence of pollution taxes in France with four different income groups and find that pollution should be taxed much below
} 
second-best rather than the first-best allocation. ${ }^{7}$ This important result holds for many utility functions that are commonly used in the environmental taxation literature: quasi-linear, homothetic (e.g., CES or Cobb-Douglas) and Stone-Geary preferences. Therefore, even if the poor spend relatively more on polluting goods, this does not necessarily imply that the optimal pollution tax should be set below the Pigouvian tax for distributional reasons. Moreover, if preferences belong to the Gorman polar class, setting the pollution tax at non-Pigouvian levels does not help to alleviate labour market distortions either. The fundamental reason behind both findings is that Engel curves for polluting goods are linear (not necessarily going through the origin) if preferences belong to the Gorman polar form. Consequently, pollution taxes have the same distributional benefits and the same labour market distortions as income taxes, but in addition also distort commodity demands. Hence, with this class of preferences, the pollution tax should not be aimed at income redistribution or at reducing labour market distortions, but only at internalising pollution externalities. We like to stress that this result does not imply that distributional motives do not matter at all for setting optimal corrective taxes, only that the incidence of the corrective tax should not guide the optimal corrective tax. As argued above, the optimal Pigouvian tax increases if the poor are hurt more by environmental damages due to equity weighting of these damages.

Fourth, if preferences belong to the Gorman polar class, and if pollution taxes are sub-optimally set below the Pigouvian tax, one can design a Pareto-improving, green tax reform that raises pollution taxes and cuts income taxes. Intuitively, if Engel curves are linear, the government can always engineer a change in the linear income tax so that every individual gets complete compensation for the increase in linear pollution taxes. Such a tax reform keeps non-environmental welfare of all individuals constant, while reducing aggregate pollution and raising government revenue. Hence, such a green tax reform unambiguously boosts social welfare Indeed, a 'double dividend' of better environmental quality and more income redistribution always exists.

Fifth, we illustrate this implication by simulating our model using a calibration on household fuel demand. Pollution taxes should be aimed at redistribution only if Engel curves deviate from linearity. The critical empirical question is thus whether Engel curves for polluting goods are linear or not and whether they contradict the assumption of Gorman polar form preferences. Often, linear expenditure systems (LES) are used to estimate fuel demand, which belong to the Gorman polar form. However, empirical evidence on the demand of fuel suggests that Engel curves are not linear, since the budget shares of individual baskets of goods appear to vary linearly in the logarithm of expenditure, suggesting that

marginal social damages for redistributional reasons. Mayeres and Proost (2001) discuss the distributional consequences of welfare-improving, revenue-neutral reforms of congestion during peak periods of car transport.

${ }^{7}$ Aigner (2014) finds that, even if second-best rules for optimal corrective taxes are the same as the first-rules, the second-best level of Pigouvian taxation depends on the second-best allocation, which is different from the first-best allocation due to distortions and available tax instruments. 
preferences are not of the Gorman polar form and that fuel is a necessity (Banks, et al., 1997). ${ }^{8,9}$ Fuel demand thus seems better described by PIGLOG preferences. To verify whether and how much pollution taxes should deviate from Pigouvian levels, we simulate our model using both LES and PIGLOG preferences, which are calibrated on estimates for fuel demand provided in Banks et al. (1997). Our simulation results show that optimal corrective taxes are indeed Pigouvian for the LES demand system and deviate from Pigouvian taxes for the PIGLOG demand system. It follows that one must be careful to conclude that the Pigouvian tax is a useful benchmark in settings with distributional concerns.

A recent strand in the literature has analysed environmental tax reform, the recycling of revenue and the effects on income distribution (e.g., Klenert and Mattauch, 2016; Klenert et al., 2016; Aubert and Chiroleu-Assouline, 2017). All these contributions employ Stone-Geary utility functions belonging to the Gorman polar class and argue that distributional consequences of pollution taxes are critically important to evaluate the consequences of green tax reforms. However, they do not recognise that optimal pollution taxes are not targeted at income redistribution with Stone-Geary utility functions. Therefore, if pollution taxes are not optimised, one can always implement a green tax reform that generates a better environment and more redistribution by a suitable adjustment of the income tax (i.e., a combination of a lower tax rate and a larger demogrant). By analysing different tax reforms, these papers may thus give the incorrect impression that distributional consequences of pollution taxes are key in the evaluation of green tax reforms. Moreover, these authors do find that a double dividend of a better environment and more equality unambiguously exists under Stone-Geary utility.

The outline of this paper is as follows. Section 2 sets up our model of income distribution and pollution damages. Section 3 derives the optimal taxes on income and pollution. Section 4 derives our key result that the optimal pollution tax should not be directed at income distributional concerns if preferences are of the Gorman polar form. Section 5 shows that Pareto-improving green tax reforms exist if pollution taxes are not at their Pigouvian levels and preferences are of the Gorman polar form. Section 6 offers some stylised simulations to illustrate our analytical results, and contrasts optimal pollution and income taxes under LES and PIGLOG preferences. Section 7 discusses the instrument set of the government, externalities in production, and general equilibrium effects. Section 8 concludes.

\footnotetext{
${ }^{8}$ A review of econometric estimates of energy demand studies can be found in Bohi and Zimmerman (1984). Many studies only consider income effects and not price effects. An excellent example of a recent empirical study of energy demand is Papageorgiou et al. (2017), which obtains an estimate of the substitution elasticity between clean and dirty energy inputs around 2-3. Apart from Banks et al. (1997), there are almost no empirical studies that estimate fully specified demand systems of the non-Gorman polar form for energy and other consumption demands that allow energy to be a necessity.

${ }^{9}$ In macroeconomics, it is also recognised that non-Gorman polar preferences often match the empirics better and thus help to explain structural transformation and growth (e.g., Boppart, 2014; Comin et al., 2015).
} 


\section{A model of income distribution and pollution damages}

A heterogeneous population of individuals differ in their (exogenous) earning ability $n \in[0, \infty)$. The population size is normalised to one. Earning ability of a worker refers to labour productivity per hour worked, which is distributed across the population according to probability density function $\mathrm{f}(n)$. Individuals derive sub-utility $\mathrm{u}\left(c_{n}, b_{n}, 1-l_{n}\right)$ from consumption of clean goods $c_{n}$, consumption of polluting ('bad') goods $b_{n}$, leisure $1-l_{n}$, where $l_{n}$ is labour supply and the time endowment of each individual is normalised to one..$^{10,11}$ The sub-utility function $\mathrm{u}(\cdot)$ is identical for all individuals, increasing, strictly concave, and twice continuously differentiable. It features positive but diminishing returns in all its arguments. In our theoretical analysis, we assume that all commodities are normal goods. ${ }^{12}$ Moreover, individuals derive disutility $D_{n} \equiv \mathrm{D}(b, n)$ from pollution, which is a function of the aggregate demand for polluting goods: $b \equiv \int_{0}^{\infty} b_{n} f(n) \mathrm{d} n$. Environmental disutility $\mathrm{D}(\cdot)$ is increasing, convex and twice continuously differentiable in aggregate pollution $b$. Marginal pollution damages $D_{b}(b, n)$ are allowed to differ between individuals of different productivity $n$. Typically, $D_{b n}(b, n)>0$ so that the poor are hurt relatively more by pollution than the rich as $D_{b}(b, n)$ increases with $n$. Total utility $U_{n}$ of each individual is the sub-utility from commodities minus disutility from pollution damages:

$$
U_{n}=\mathrm{u}\left(c_{n}, b_{n}, 1-l_{n}\right)-\mathrm{D}(b, n) .
$$

By assuming that environmental disutility enters utility additively, we focus on the distributional aspects of the pollution tax and environmental quality and abstract from second-best interactions of environmental quality with distortions in labour and goods markets. ${ }^{13}$

The government sets a linear income tax with rate $t$ and non-individualised lump-sum transfer $s$. The ad valorem pollution tax is also linear and has rate $q$. The informational requirements to employ linear tax instruments are that the government must be able to verify aggregate labour income and aggregate consumption of polluting commodities. ${ }^{14}$ The household budget constraint is:

$$
c_{n}+(1+q) b_{n}=(1-t) n l_{n}+s .
$$

Wages per efficiency unit of labour, the price of clean goods, and the before-tax price of polluting goods

\footnotetext{
${ }^{10}$ In the remainder, Roman letters denote functions and subscripts denote derivatives (except ability $n$ ).

${ }^{11}$ One may interpret labour supply in broad terms, including all intensive-margin responses, such as intensity of work, entrepreneurial effort, occupational choice, human capital investment, labour supplied to the formal sector rather than to the informal sector (e.g. household production), and tax avoidance and evasion (e.g. via the black market). Hence, the labour supply elasticity in the model corresponds to the elasticity of taxable income (ETI).

${ }^{12}$ In the simulations, however, we allow polluting goods demand to be inferior under the PIGLOG demand system.

${ }^{13}$ See Jacobs and De Mooij (2015) for a complete characterisation of the optimal tax system using general utility functions and a traditional social welfare function.

${ }^{14}$ We postpone the discussion of the consequences of allowing for non-linear instruments that depend on individual labour earnings or polluting goods demands to Section 7.
} 
are all normalised to one. The first-order conditions for labour supply and commodity demands are given by $\mathrm{u}_{1-l} / \mathrm{u}_{c}=(1-t) n$ and $\mathrm{u}_{b} / \mathrm{u}_{c}=1+q$. Indirect utility $v_{n}$ is given by $v_{n} \equiv \mathrm{v}(t, q, s, b, n)$. Its derivatives follow from Roy's identity: $\partial v_{n} / \partial s=\eta_{n}, \partial v_{n} / \partial t=-\eta_{n} n l_{n}, \partial v_{n} / \partial q=-\eta_{n} b_{n}$, and $\partial v_{n} / \partial b=\mathrm{D}_{b}(b, n)$, where $\eta_{n}$ denotes the marginal private utility of income of individual $n$. We define the compensated elasticities of labour supply and demand for dirty goods as follows: $\varepsilon_{l t} \equiv\left(\partial l_{n}^{c} / \partial t\right)(1-t) / l_{n}<0$, $\varepsilon_{b t} \equiv\left(\partial b_{n}^{c} / \partial t\right) /(1-t) / b_{n}, \quad \varepsilon_{l q} \equiv\left(\partial l_{n}^{c} / \partial q\right)(1+q) / l_{n} \quad$ and $\quad \varepsilon_{b q} \equiv\left(\partial b_{n}^{c} / \partial q\right)(1+q) / b_{n}<0, \quad$ where $\quad$ a superscript $c$ denotes a compensated (Hicksian) change.

The government budget constraint states that revenue from income and pollution taxes minus the cost of lump-sum transfers must cover an exogenous public revenue requirement $R$ :

$$
R=\int_{0}^{\infty}\left(t n l_{n}+q b_{n}-s\right) \mathrm{f}(n) \mathrm{d} n
$$

The government maximises social welfare $W$, which is a weighted sum of the individual utilities:

$$
W \equiv \int_{0}^{\infty} \omega_{n} v_{n} \mathrm{f}(n) \mathrm{d} n, \int_{0}^{\infty} \omega_{n} \mathrm{f}(n) \mathrm{d} n=1, \omega_{n}>0, \forall n,
$$

where $\omega_{n}$ is the Pareto weight of individual $n$. Without loss of generality, we normalise the sum of the Pareto weights to one. By denoting $\lambda$ as the multiplier on the government budget constraint in eq. (3), we define the marginal social welfare weight of individual $n$ as $g_{n} \equiv \omega_{n} \eta_{n} / \lambda$. Here $g_{n}$ captures the increase in social welfare - measured in money units - if individual $n$ receives an additional euro in income. This equals the welfare weight $\omega_{n}$ applied to the increase in private utility $\eta_{n}$, which is divided by the marginal social value of public revenue to convert from utility to money units. Our formulation in terms of Pareto weights allow us to remain agnostic about the specific distributional objectives of the government, since we do not a priori impose any structure on the pattern of Pareto weights. Naturally, we can derive the social welfare weights from a social welfare function, as is usual in most optimal tax analyses. For example, the concave social welfare function $\Psi\left(v_{n}\right), \Psi^{\prime}>0, \Psi^{\prime \prime} \leq 0$, gives $\omega_{n}=\Psi^{\prime}\left(v_{n}\right)$, and social welfare weights $g_{n} \equiv \Psi^{\prime}\left(v_{n}\right) \eta_{n} / \lambda$ smoothly decline with income. The weights $g_{n}$ can also be interpreted as generalised social welfare weights that are a function of individual characteristics, taxes or non-welfarist objectives such as concerns for fairness, hard work, or sacrifice (e.g., Saez and Stantcheva, 2016). Finally, our characterisation of the optimal tax system describes a Pareto-optimal tax structure. This follows from minimising public resources $R$ in eq. (3) subject to a set of constraints on the distribution of utilities $v_{n} \geq \overline{v_{n}}, \forall n$, where $\overline{v_{n}}$ is an exogenously given level of utility for individual $n$ (e.g., the utility in absence of government intervention). If we define $\omega_{n} / \lambda$ as the multiplier on each utility constraint, then the social welfare weights are equal to $g_{n} \equiv \omega_{n} \eta_{n} / \lambda$ if the utility constraint is binding and $g_{n}=0$ if the utility constraint does not bind. 


\section{Optimal income and pollution taxes}

The government maximises social welfare (4) subject to the government budget constraint (3) with $\lambda$ as its Lagrange multiplier. To facilitate the characterisation of optimal tax policy, we employ Diamond's (1975) social marginal welfare weights:

$$
g_{n}^{*} \equiv g_{n}+\operatorname{tn} \frac{\partial l_{n}}{\partial s}+\left(q-q^{P}\right) \frac{\partial b_{n}}{\partial s},
$$

where $q^{P}$ denotes the first-best, Pigouvian corrective tax, which we will define in Proposition 1 below. The Diamond-based social welfare weights thus consist of the standard social welfare weight $g_{n} \equiv \omega_{n} \eta_{n} / \lambda$ of individual $n$ plus the income effects on social welfare as a result of the transfer $s$. If the transfer to individual $n$ generates income effects on taxed bases, the welfare weights change from $g_{n}$ to $g_{n}^{*}$. The term $t_{n} \partial l_{n} / \partial s$ is due to the income effect on labour supply. A higher transfer depresses labour tax revenue, and thereby reduces social welfare (provided the labour income tax rate is strictly positive). The term $\left(q-q^{P}\right) \partial b_{n} / \partial s$ is due to the income effect in demand for polluting goods. A higher transfer lowers (raises) social welfare if the pollution tax is below (above) the Pigouvian tax (i.e., $q<q^{P}$ ). Larger tax revenue then does not (does) compensate for the reduction in environmental quality.

We also introduce Feldstein (1972)'s distributional characteristics of labour income $n l_{n}$ and polluting consumption $b_{n}$ as follows:

$$
\begin{gathered}
\xi_{l} \equiv \frac{\int_{0}^{\infty}\left(1-g_{n}^{*}\right) n l_{n} f(n) \mathrm{d} n}{\int_{0}^{\infty} g_{n}^{*} f(n) \mathrm{d} n \int_{0}^{\infty} n l_{n} f(n) \mathrm{d} n}=\frac{-\operatorname{cov}\left[g_{n}^{*}, n l_{n}\right]}{\mathrm{E}\left[g_{n}^{*}\right] \mathrm{E}\left[n l_{n}\right]}, \\
\xi_{b} \equiv \frac{\int_{0}^{\infty}\left(1-g_{n}^{*}\right) b_{n} f(n) \mathrm{d} n}{\int_{0}^{\infty} g_{n}^{*} f(n) \mathrm{d} n \int_{0}^{\infty} b_{n} f(n) \mathrm{d} n}=\frac{-\operatorname{cov}\left[g_{n}^{*}, b_{n}\right]}{\mathrm{E}\left[g_{n}^{*}\right] \mathrm{E}\left[b_{n}\right]},
\end{gathered}
$$

where $\operatorname{cov}\left[g_{n}^{*}, x_{n}\right]$ is de covariance between Diamond's social welfare weight $g_{n}^{*}$ for $x_{n}=l_{n}, b_{n}$, and $\mathrm{E}\left[x_{n}\right] \equiv \int_{0}^{\infty} x_{n} f(n) \mathrm{d} n$ denotes the expectations operator for variable $x_{n}$. The characteristics $\xi_{l}$ and $\xi_{b}$, capture how strongly the social welfare weights correlate with the tax bases. They measure the social marginal value - expressed in money units as a fraction of the tax base - of an additional resource unit of income redistribution by raising the tax rate on that base. The Feldstein's distributional characteristics lie between minus and plus one, since it is the normalised covariance between the social welfare weights $g_{n}^{*}$ and the contribution of each individual to the tax base. Assuming that Diamond's marginal social welfare 
weights $g_{n}^{*}$ decline with income, the normalised covariance is negative for the income tax base, and thus $\xi_{l}>0$. Intuitively, taxing income provides social benefits, since the highest income earners have the lowest welfare weights.

If social welfare weights also decline with demand for polluting consumption, $\xi_{b}>0$. Taxing polluting goods yields distributional benefits as well. An example where this could be the case is airline travel. However, the social welfare weights may increase in polluting consumption if the poor consume more polluting goods than the rich do, that is, if polluting goods are inferior. In that case, Feldstein's distributional characteristic for polluting goods is negative $\left(\xi_{b}<0\right)$, and taxing these goods yields distributional losses. Note that we have ruled this out by assuming that all commodities are normal in the theoretical analysis. Hence, both distributional characteristics are always positive $\left(\xi_{l}>0, \xi_{b}>0\right)$ provided that the social welfare weights $g_{n}^{*}$ are non-increasing. ${ }^{15}$

The Feldstein characteristics (6a) and (6b) are zero only if Diamond's marginal social welfare weights $g_{n}^{*}$ are constant across all individuals. This is the case if the social welfare function is utilitarian $\left(\omega_{n}=1\right.$ for all $\left.n\right)$ and the private marginal utility of income $\eta_{n}$ is constant, hence $g_{n}=\omega_{n} \eta_{n} / \lambda=\eta_{n} / \lambda$ is independent of $n$. In that case, we find that $t=0$ and $q=q^{P}$ so that $g_{n}^{*}=g_{n}=1$. For a Rawlsian social welfare function $\left(\omega_{0}>0\right.$, and $\omega_{n}=0$ for all other $\left.n\right), \xi_{l}$ and $\xi_{b}$ converge to 1 if the earnings ability of the lowest individual converges to zero. With smoothly declining Pareto weights $\omega_{n}$, the Feldstein characteristics are positive and smaller than 1 .

We use a bar to denote an income-weighted variable $x: \bar{x} \equiv \int_{0}^{\infty} n l_{n} x_{n} \mathrm{f}(n) \mathrm{d} n / \int_{0}^{\infty} n l_{n} \mathrm{f}(n) \mathrm{d} n$. We denote the marginal propensity to consume dirty goods out of labour income by $\beta_{n} \equiv(1+q) b_{n} /((1-$ t) $\left.n l_{n}\right)$ ). Armed with this notation, we can derive the first proposition on optimal income redistribution and pollution taxes.

Proposition 1 - The optimal equity-weighted Pigouvian tax, the optimal pollution tax, the optimal marginal income tax rate, and the marginal cost of public funds are determined by:

$$
\begin{aligned}
& q^{P} \equiv \int_{0}^{\infty} \omega_{n} \frac{\mathrm{D}_{b}(b, n)}{\lambda} f(n) \mathrm{d} n=\int_{0}^{\infty} g_{n} \frac{\mathrm{D}_{b}(b, n)}{\eta_{n}} f(n) \mathrm{d} n, \\
& \xi_{b}=\frac{t}{1-t}\left(\frac{-\overline{\varepsilon_{l q}}}{\bar{\beta}}\right)+\frac{q-q^{P}}{1+q}\left(\frac{-\overline{\beta \varepsilon_{b q}}}{\bar{\beta}}\right),
\end{aligned}
$$

\footnotetext{
${ }^{15}$ In our simulations with PIGLOG preferences, polluting goods demand can be inferior, however, at higher income
} levels. 


$$
\begin{aligned}
& \xi_{l}=\frac{t}{1-t}\left(-\overline{\varepsilon_{l t}}\right)+\frac{q-q^{P}}{1+q}\left(-\overline{\beta \varepsilon_{b t}}\right), \\
& M C P F \equiv 1 / \int_{0}^{\infty} g_{n}^{*} \mathrm{f}(n) \mathrm{d} n=1 .
\end{aligned}
$$

Proof: See Appendix A.

The Pigouvian tax is defined in eq. (7). It exactly internalises all damages associated with polluting consumption by all individuals in society. The condition for the optimal corrective tax is given in eq. (8). The primary goal of corrective taxes is to internalise pollution externalities. In the absence of labour market distortions $(t=0)$ and redistributional objectives $\left(\xi_{b}=0\right)$, the optimal pollution tax equals the Pigouvian tax: $q=q^{P}$. The Pigouvian tax depends on distributional concerns for two reasons. First, the shadow value of public funds $\lambda$ is higher in countries with a more unequal income distribution. Second, the impacts of environmental damages are distributed unequally across the population. We discuss both in turn.

First, to illustrate the impact of the shadow value of public funds $\lambda$, consider the case where marginal environmental damages are constant across individuals (i.e., $D_{b n}(b, n)=0$ ), and write these as $D_{b}(b, n)=\mathrm{D}^{\prime}(b)$. Then, the Pigouvian tax equals $q^{P}=\mathrm{D}^{\prime}(b) / \lambda$. Moreover, if there are no distortionary taxes $(t=0)$, and optimal corrective taxes are Pigouvian $\left(q=q^{P}\right)$, the shadow value of public funds boils down to $\lambda=\int_{0}^{\infty} \omega_{n} \eta_{n} \mathrm{f}(n) \mathrm{d} n$, which follows from eq. (10) with $g_{n}^{*}=g_{n}=\omega_{n} \eta_{n} / \lambda$. Consequently, the shadow value of public funds is larger in more unequal societies (i.e., more dispersion in $\eta_{n}$ ) or if governments are more inequality averse (i.e., Pareto weights $\omega_{n}$ decline faster). Hence, Pigouvian taxes are then lower (cf. Aigner, 2014). If public resources are relatively scarce, providing the public good of a better environment thus competes with the public good of redistributing income.

Second, environmental damages are not necessarily constant across individuals. The Pigouvian tax in eq. (7) weights the environmental damages of individual $n$ with the social welfare weight $g_{n}$ of that individual. Consequently, our formulation captures the literature that applies 'equity weights' to discount environmental damages (cf. Mirrlees, 1978; Anthoff et al., 2009; Anthoff and Tol, 2010). ${ }^{16}$ Indeed, the correct equity weights are the standard social welfare weights $g_{n}$, not the Diamond social welfare

\footnotetext{
16 The climate-economics literature has adopted equity weighs in calculating the social cost of carbon (i.e., the Pigouvian tax on carbon emissions) so as to capture trade-offs between present and future generations (e.g., Bruce et al., 1995; Anthoff and Tol, 2010). Equity weights that decline with income or consumption typically push up the social cost of carbon. However, if equity weights are applied both across space and time, equity weighting can increase the cost of carbon (e.g., Anthoff et al., 2009; Nordhaus, 2014).
} 
weights $g_{n}^{*}$ that adjust for income effects on taxed bases. If poor individuals have higher social welfare weights $g_{n}$, and suffer larger marginal damages from aggregate pollution (i.e., $D_{b n}<0$ ), then the Pigouvian tax is higher. Similarly, the Pigouvian tax is lower if the rich have lower social welfare weights $g_{n}$, and they bear the consequences of environmental damage (i.e., $D_{b n}>0$ ).

To illustrate the equity weighting of environmental damages further, consider a linear pollution damage function of the form $\mathrm{D}(b, n) \equiv \omega_{n}^{b} b$, where $\omega_{n}^{b}$ measures the marginal utility loss to individual $n$ if aggregate pollution $b$ increases by one unit. $\omega_{n}^{b}$ is thus the 'pollution weight' of individual $n$. Defining the aggregate pollution weight as $\omega^{b} \equiv \int_{0}^{\infty} \omega_{n}^{b} \mathrm{f}(n) \mathrm{d} n$, the Pigouvian corrective tax becomes:

$$
q^{P}=\left(\omega^{b}+\operatorname{cov}\left[\omega_{n}, \omega_{n}^{b}\right]\right) / \lambda .
$$

Hence, if the poor (rich) suffer disproportionately from pollution, the covariance between the pollution weights $\omega_{n}^{b}$ and the welfare weights $\omega_{n}$ is positive (negative), and the Pigouvian tax is bigger (smaller) than the sum of the marginal damages, $\omega^{b} / \lambda$, to reflect the higher (lower) welfare weight given to the poor.

The optimal pollution tax in eq. (8) generally differs from the Pigouvian tax derived in eq. (7). The optimal pollution tax in eq. (8) equates the distributional benefits of setting a higher corrective tax (the left-hand side) to the deadweight losses in the labour market (first term on the right-hand side) and the deadweight losses in the goods market (second term on the right-hand side). In second-best settings with distortionary taxation and income redistribution, the corrective pollution tax thus serves two other roles besides internalising pollution externalities. First, if the corrective tax entails distributional gains, $\xi_{b}>0$, pollution taxes contribute to redistributing income. Consequently, optimal pollution taxes should be set at rates that are higher than dictated by the Pigouvian level - ceteris paribus. If, however, the incidence of corrective taxes is regressive, $\xi_{b}$ is lower and the distributional gains are lower. Consequently, corrective taxes should be lowered accordingly - ceteris paribus. Second, a corrective pollution tax generally exacerbates labour market distortions, since indirect taxes also increase the total tax wedge on labour supply. This curbs labour supply further below socially optimal levels (provided that $\left.\varepsilon_{l q}<0\right) .{ }^{17}$ Hence, if pre-existing labour market distortions are more severe (higher $t$ or higher $-\varepsilon_{l q}$ ) optimal corrective taxes should be set more below the Pigouvian level - ceteris paribus. This argument for setting non-Pigouvian corrective taxes goes back to Corrlett and Hague (1953), who demonstrate that - in settings without pollution externalities - non-uniform commodity taxes are optimal if some commodities

\footnotetext{
${ }^{17}$ We note that the sign of $\varepsilon_{l q}$ is generally ambiguous, and the arguments reverse if $\varepsilon_{l q}>0$. For most often-used utility functions, this case can, however, be ruled out, see Jacobs and De Mooij (2011).
} 
are stronger complements with leisure than others. ${ }^{18}$ In our setting, optimal pollution taxes should be higher (lower) than the Pigouvian rate if polluting goods are stronger (weaker) complements to leisure than are clean goods.

Redistributing income or alleviating labour market distortions comes at a price of distorting commodity demands. If the optimal pollution tax is set above the Pigouvian level (i.e., $q>q^{P}$ ), raising the corrective tax generates distortions in the demand for polluting goods, and more so if this demand is more elastic $\left(\varepsilon_{b q}\right.$ larger). But, if the optimal pollution tax is set below the Pigouvian rate $\left(q<q^{P}\right)$, raising the corrective tax alleviates goods market distortions by moving the pollution tax closer to the Pigouvian rate.

The optimal income tax in eq. (9) equates the distributional benefits of setting a higher income tax (the left-hand side) to the deadweight losses in the labour market (first term on the right-hand side) and the deadweight losses in the goods market (second term on the right-hand side). Intuitively, the larger are the distributional benefits of income taxes, the larger should the optimal income tax rate be. The more elastically labour supply responds to taxation $\left(-\varepsilon_{l t}\right.$ larger), the lower should the optimal income tax rate be - ceteris paribus. If the corrective tax is set above the Pigouvian level $\left(q>q^{P}\right)$, and income taxes reduce demand for polluting commodities $\left(\varepsilon_{b t}<0\right)$, the income tax exacerbates goods market distortions, and more so if the demand for polluting commodities is more elastic $\left(-\varepsilon_{b t}\right.$ larger). However, if the corrective tax is set below the Pigouvian rate $\left(q<q^{P}\right)$, the income tax reduces goods market distortions. A higher income tax then reduces the demand for polluting commodities. This raises social welfare if the optimal pollution tax is set below the Pigouvian rate - ceteris paribus. ${ }^{19}$

Eqs. (8) and (9) can be solved to derive the optimal income and pollution taxes as functions of the distributional characteristics and the weighted elasticities:

(8') $\frac{q-q^{P}}{1+q}=\frac{\xi_{b} \overline{\varepsilon_{l t}}-\xi_{l} \overline{\varepsilon_{l q}} / \bar{\beta}}{\Delta}$,

$$
\frac{t}{1-t}=\frac{\xi_{l} \overline{\beta \varepsilon_{b q}} / \bar{\beta}-\xi_{b} \overline{\beta \varepsilon_{b t}}}{\Delta}
$$

where $\Delta \equiv \overline{\varepsilon_{l q}} \overline{\beta \varepsilon_{b t}} / \bar{\beta}-\overline{\varepsilon_{l t}} \overline{\beta \varepsilon_{b q}} / \bar{\beta}<0$. The interpretation of these follows from the discussion above.

Finally, eq. (10) shows that the marginal cost of public funds (MCPF) equals 1 in the optimal tax system. The reason is that the government changes the transfer $s$ such that the marginal value of one unit

\footnotetext{
${ }^{18}$ These results have been generalised to settings with linear taxes and income redistribution (Diamond and Mirrlees, 1971; Diamond, 1975) and non-linear taxes and income redistribution (Atkinson and Stiglitz, 1976; Jacobs and Boadway, 2014).

${ }^{19}$ We note that in general the sign of $\varepsilon_{b q}$ is not unambiguous, see also footnote 17.
} 
of resources is the same in the public sector (1) and the private sector $\left(\int_{0}^{\infty} g_{n}^{*} \mathrm{f}(n) \mathrm{d} n\right)$. Alternatively, distortions in labour or goods markets are present only because they generate either distributional or environmental benefits, as also eqs. (8) and (9) demonstrate. Consequently, economic distortions are the price of redistribution or a better environment, and not the price of raising public revenue. After all, the government always has access to a non-distortionary marginal source of finance (the non-individualised lump-sum transfer). Raising public revenue is thus not a task of the income tax or of the corrective pollution tax (Jacobs and De Mooij, 2015). Consequently, if the analysis is extended to allow for public goods, the optimal provision follows from the modified Samuelson rule, and no corrections need to be made for the $M C P F$, in contrast to the results of Wendner (2014). See also Jacobs (2017).

\section{Gorman polar preferences}

Many applications assume that utility is weakly separable between commodities and labour, i.e., $U_{n}=\mathrm{u}\left(\mathrm{h}\left(c_{n}, b_{n}\right), 1-l_{n}\right)-\mathrm{D}(b, n)$, with a sub-utility function $\mathrm{h}(\cdot)$ that belongs to the Gorman (1961) polar form. ${ }^{20}$ This section demonstrates that in this case the (regressive) incidence of pollution taxes should not determine optimal corrective taxes.

Definition 1 - The sub-utility function $h_{n}=\mathrm{h}\left(c_{n}, b_{n}\right)$ for individual $n$ is of the Gorman (1961) polar form if its corresponding indirect utility function is of the form $h_{n}=v\left(q, m_{n}\right)=\left(m_{n}-\varphi(q)\right) / \mathrm{p}(q)$, where $m_{n} \equiv(1-t) n l_{n}+s$ is net disposable income, $\partial h_{n} / \partial m_{n}=1 / \mathrm{p}(q)$ denotes the marginal sub-utility of income, and $\varphi(q)$ is the expenditure to obtain zero sub-utility. Both $\mathrm{p}(q)$ and $\varphi(q)$ are the same for all individuals. The expenditure function is $m_{n}=\mathrm{p}(q) h_{n}+\varphi(q)$.

Marshallian demand for polluting goods follows from application of Roy's identity:

$$
b_{n}=-\frac{\partial v / \partial q}{\partial v / \partial m_{n}}=\varphi^{\prime}(q)+\frac{\mathrm{p}^{\prime}(q)}{\mathrm{p}(q)}\left(m_{n}-\varphi(q)\right) .
$$

Consequently, the Engel curve is linear for all preferences that are of the Gorman polar form, which

\footnotetext{
${ }^{20}$ We also make the assumption of weak separability, since we wish to focus on the case where all commodity taxes are uniform in the absence of environmental externalities if preferences are Gorman polar (cf. Deaton, 1977). Empirical studies generally find weak evidence that labour supply is weakly separable from commodity demand (e.g., Meghir and Browning, 1991; Crawford et al., 2010; Pirttilä and Suoniemi, 2014). Nevertheless, no clear-cut patterns in commodity demands and labour supply emerge from this literature, only in some obvious cases, such as child-care services. Moreover, many studies in environmental economics and macroeconomics assume weakly separable preferences between commodity demands and labour supply.
} 
allows for aggregation over all individuals. For later reference, we rewrite the demand for polluting goods as:

$$
(1+q) b_{n}=\alpha(q)+\phi(q) m_{n},
$$

where the coefficients $\alpha(q) \equiv(1+q)\left(\varphi^{\prime}(q)-\varphi(q) \mathrm{p}^{\prime}(q) / \mathrm{p}(q)\right)$ and $\phi(q) \equiv(1+q) \mathrm{p}^{\prime}(q) / \mathrm{p}(q)$ are the same for everyone. ${ }^{21}$

We now provide some examples of the Gorman polar form (see Appendix B for derivations):

- Quasi-linear preferences: $\mathrm{h}\left(c_{n}, b_{n}\right)=c_{n}+\mathrm{k}\left(b_{n}\right), \mathrm{k}^{\prime}>0, \mathrm{k}^{\prime \prime}<0$. Demand for polluting goods is $b_{n}=\kappa(q)$ with $\kappa^{\prime}(q)=1 / \mathrm{k}^{\prime \prime}\left(b_{n}\right)$ from $\mathrm{k}^{\prime}\left(b_{n}\right)=1+q$. Hence, we have $\alpha(q) \equiv(1+q) \kappa(1+q), \quad \phi(q)=0$, $\mathrm{p}(q)=1$, and $\varphi(q)=(1+q) \kappa(1+q)-\mathrm{k}(\kappa(1+q))$.

- $\quad$ Standard Stone-Geary preferences: $\mathrm{h}\left(c_{n}, b_{n}-\bar{b}\right)=\left(c_{n} /(1-a)\right)^{1-a}\left(\left(b_{n}-\bar{b}\right) / a\right)^{a}, 0<a<1$, where $\bar{b}$ is the subsistence level for the consumption of polluting goods. Demand for polluting goods is $b_{n}=(1-a) \bar{b}+a m_{n} /(1+q)$. Hence, we have $\alpha(q) \equiv(1+q)(1-a) \bar{b}, \quad \phi(q)=a, \mathrm{p}(q)=(1+q)^{a} \quad$ and $\varphi(q)=(1+q) \bar{b}$. This specification leads to the Linear Expenditure System. See also (18) below.

- $\quad$ Generalised Stone-Geary preferences: $\mathrm{h}\left(c_{n}, b_{n}-\bar{b}\right)=\left[(1-a) c_{n}^{(\sigma-1) / \sigma}+a\left(b_{n}-\bar{b}\right)^{(\sigma-1) / \sigma}\right]^{\sigma /(\sigma-1)}$, $0<a<1$ and $\sigma>0$, where $\bar{b}$ is the subsistence level for the consumption of polluting goods. Demand for polluting goods is: $b_{n}=\left(1+(1+q)^{\sigma-1}((1-a) / a)^{\sigma}\right)^{-1} m_{n} /(1+q)+\left(1+(1+q)^{1-\sigma}(a /(1-a))^{\sigma}\right)^{-1} \bar{b}$. Hence, we $\quad$ have $\quad \alpha(q) \equiv\left(1+a^{\sigma}(1-a)^{-\sigma}(1+q)^{1-\sigma}\right)^{-1}(1+q) \bar{b}, \quad \phi(q)=\left(1+(1-a)^{\sigma} a^{-\sigma}(1+q)^{\sigma-1}\right)^{-1}$, $\mathrm{p}(q)=(1-a)^{\sigma /(1-\sigma)}\left(1+a^{\sigma}(1-a)^{-\sigma}(1+q)^{1-\sigma}\right)^{1 /(1-\sigma)}$, and $\varphi(q)=(1+q) \bar{b}$.

These three examples correspond to non-homothetic preferences. The class of homothetic preferences is nested within the class of Gorman polar form preferences by setting $\varphi(q)=0$. For example, Cobb-Douglas and CES preferences are nested in the standard and generalised Stone-Geary preferences, respectively, if the subsistence level of consumption of polluting goods is set to zero (i.e., $\bar{b}=0)$.

Proposition 2 shows that with Gorman polar form preferences the optimal rule for the optimal pollution tax is the same as the first-best rule, i.e., the pollution tax is set at the Pigouvian level.

${ }^{21} \phi(q)=\left((1+q) b_{n}-\alpha(q)\right) / m_{n}$ is the marginal propensity to consume polluting goods out of net labour income. If $\alpha(q)>0$, then $\phi(q)$ is smaller than the expenditure share $(1+q) b_{n} / m_{n}$, which is the average propensity to consume polluting goods out of net labour income, and vice versa if $\alpha(q)<0$. 
Proposition 2 - If the utility function is $U_{n}=\mathrm{u}\left(\mathrm{h}\left(c_{n}, b_{n}\right), 1-l_{n}\right)-\mathrm{D}(b, n)$, where $\mathrm{h}\left(c_{n}, b_{n}\right)$ is of the Gorman (1961) polar form and identical for all individuals, the optimal pollution tax, the optimal marginal income tax rate, and the marginal cost of public funds are determined by:

$$
\begin{aligned}
& q=q^{P} \equiv \int_{0}^{\infty} g_{n} \frac{\mathrm{D}_{b}(b, n)}{\eta_{n}} \mathrm{f}(n) \mathrm{d} n, \\
& \frac{t}{1-t}=\frac{\xi_{l}}{-\overline{\varepsilon_{l t}}}, \\
& M C P F \equiv 1 / \int_{0}^{\infty} g_{n}^{*} \mathrm{f}(n) \mathrm{d} n=1 .
\end{aligned}
$$

Proof: See Appendix C.

If preferences are weakly separable and sub-utility is of the Gorman polar form, the optimal corrective pollution tax in eq. (13) is solely aimed at internalising pollution externalities, not at redistributing income or reducing labour market distortions. Consequently, the optimal corrective tax is set at the Pigouvian level, even if the poor spend a larger fraction of their income on consumption of polluting goods. The reason is that with Gorman polar preferences the Engel curves of polluting goods are linear in labour earnings. At the margin, individuals have the same marginal propensities to consume polluting goods out of their net income. Consequently, linear corrective pollution taxes have equivalent marginal distributional benefits as linear taxes on labour earnings. Similarly, if the demand for polluting consumption goods features a linear Engel curve, linear pollution taxes cause identical distortions in labour supply as linear income taxes with the same revenue. Although corrective pollution taxes have the same distributional benefits and the same labour market distortions as income taxes, they also distort commodity demands. Consequently, there are no redistributional or efficiency reasons to set corrective taxes at non-Pigouvian rates if preferences are Gorman polar. The optimal pollution tax is then aimed solely at internalising pollution externalities and is set at the first-best, Pigouvian level. ${ }^{22}$ Proposition 2 generalises Corollary 1 in Jacobs and De Mooij (2015) for weakly separable homothetic sub-utility functions without income effects to any Gorman polar form sub-utility function with income effects.

Although we have shown that the optimal decision rule for second-best pollution taxes is the same as in first-best settings, optimal pollution taxes are generally different in second-best settings as optimal allocations differ in first- and second-best outcomes. In particular, the total amount of pollution $b$,

\footnotetext{
${ }^{22}$ This result is the environmental-tax counterpart to the findings by Sandmo (1975) and Deaton (1977) on the desirability of uniform linear commodity taxes. Our findings apply to the pollution tax net of the Pigouvian tax, i.e., $q-q^{P}$.
} 
the private marginal utility of income $\eta_{n}$, and the social welfare weights $g_{n}$ are typically not the same in the first-best and second-best optima.

Finally, Corollary 1 derives a special case of Proposition 2 where we assume preferences that feature constant private marginal utility of income, no income effects in labour supply, and uniform marginal environmental damages over the population.

Corollary 1 - Assume that utility is quasi-linear: $\mathrm{u}\left(\mathrm{h}\left(c_{n}, b_{n}\right), 1-l_{n}\right)=\mathrm{h}\left(c_{n}, b_{n}\right)-l_{n}^{1+1 / \vartheta} /(1+1 / \vartheta)$, where $\vartheta>0$ and $\mathrm{h}\left(c_{n}, b_{n}\right)$ is of the Gorman (1961) polar form. Assume also that marginal environmental damages are independent from ability: $D_{b}(b, n) \equiv D^{\prime}(b)$. Then, labour supply is $l_{n}=((1-t) n / \mathrm{p}(q))^{\vartheta}$, the optimal pollution tax is $q=q^{P}=\mathrm{p}(q) \mathrm{D}^{\prime}(b)$, and the optimal labour income tax rate follows from $t /(1-t)=\xi_{l} / \vartheta$, where the Diamond welfare weights are $g_{n}^{*}=g_{n}, \forall n$. If Pareto weights are the same for all individuals $\left(g_{n}=1, \forall n\right)$, then the optimal income tax rate is zero $(t=0)$.

Proof: See Appendix D.

If sub-utility is quasi-linear, the optimal pollution tax is Pigouvian, and equals marginal pollution damages $q=\mathrm{p}(q) \mathrm{D}^{\prime}(b)$. The optimal income tax rate depends positively on demand for income redistribution and varies inversely with the compensated elasticity of labour supply $\vartheta{ }^{23}$

\section{Green tax reforms}

Policy makers may find it hard to implement an optimal income and pollution tax system. It is therefore relevant to investigate the question whether welfare-improving tax reforms exist that raise pollution taxes and reduce income taxes if the starting position is one where the initial income and pollution taxes are not at their optimal levels from Proposition 1. We do so by considering a net-income neutral tax reform, which is similar in spirit to Kaplow (2012). In particular, we analyse a tax reform that keeps net incomes, and, thereby, non-environmental utility $\mathrm{u}(\cdot)$, of all individuals fixed, while environmental damages are allowed to change. We ask the question whether such a net-income neutral increase in the pollution tax raises social welfare. That is, are reductions in aggregate pollution damages sufficiently large that they compensate for any public revenue shortfalls? Proposition 3 provides the answer.

\footnotetext{
${ }^{23}$ See also Boadway and Tremblay (2008), who analyse optimal corrective taxation and optimal redistribution with preferences that are quasi-linear in labour.
} 
Proposition 3 - Assume that the utility function is $U_{n}=\mathrm{u}\left(\mathrm{h}\left(c_{n}, b_{n}\right), 1-l_{n}\right)-\mathrm{D}(b, n)$, where $\mathrm{h}\left(c_{n}, b_{n}\right)$ is of the Gorman polar form. Consider an environmental tax reform that raises pollution taxes $(\mathrm{d} q>0)$ and keeps net incomes and non-environmental welfare of all individuals constant $\left(\mathrm{d} u_{n}=0\right)$ by lowering the income tax and raising the transfer such that

$$
\mathrm{d} t=-\frac{\phi(q)(1-t)}{1+q} \mathrm{~d} q<0 \text { and } \mathrm{d} s=\left(\frac{\alpha(q)+\phi(q) s}{1+q}\right) \mathrm{d} q>0 .
$$

Social welfare $W$ rises (falls) under this tax reform if the pollution tax is below (above) the Pigouvian tax:

$$
\left.\frac{1}{\lambda} \frac{\mathrm{d} W}{\mathrm{~d} q}\right|_{\text {reform }}=\int_{0}^{\infty} \frac{\left(q^{P}-q\right)}{(1+q)}\left(\phi(q) \varepsilon_{b t}-\varepsilon_{b q}\right) b_{n} \mathrm{f}(n) \mathrm{d} n .
$$

Proof: See Appendix E for the proof of (16) and (17) and Appendix C for the proof that $\phi(q) \varepsilon_{b t}>\varepsilon_{b q}$.

If preferences are identical for all individuals and are of the Gorman polar form, both the slope and the intercept of the Engel curve are the same for all individuals. Hence, the government can implement a tax reform that simultaneously raises pollution taxes $q$ and the transfer $s$, while lowering the tax rate $t$, such that everyone's non-environmental utility u(·) remains constant, see eq. (16). Since the changes in policy instruments are identical for all individuals, this green tax reform is implementable. The only reason why the government would implement such a tax reform is that it brings the tax system closer to the secondbest optimum, since it does not use the pollution tax for reducing labour market distortions or redistributing incomes. Eq. (17) of Proposition 3 demonstrates that if corrective taxes $q$ are lower (higher) than the Pigouvian rate $q^{P}$, the distribution neutral environmental tax reform in eq. (16) raises (lowers) social welfare. Hence, if the government prices pollution insufficiently, it is possible to recycle revenues from a higher pollution tax in such a way that none of the individuals' non-environmental utilities is affected, whilst aggregate damages from pollution fall. This striking result follows (again) from the fact that Engel curves for polluting goods are linear.

Proposition 3 breaks down if preferences are not of the Gorman polar form. The government can then no longer implement a green reform that raises the pollution tax, lowers the income tax, and raises the transfer, so that everyone's non-environmental utility is unaffected. Hence, if preferences are not Gorman polar, then the incidence of pollution taxes does determine their desirability - as we demonstrated in Proposition 1.

The derivation of Proposition 3 does not require that the income tax system is optimised, and holds for any arbitrary income tax system $(t, s)$ with any arbitrary $M C P F$. However, if the income tax is optimised, the $M C P F$ is unity (cf. eq. (15) of Proposition 2). The optimal linear income tax and transfer follow from the expression for the optimal income tax in eq. (14) and the government budget constraint in 
eq. (3).

If preferences are of the Gorman polar form, Proposition 3 demonstrates that the government can design net-income neutral adjustments of the income tax even if the poor - on average - spend a larger fraction of their income on polluting goods. Proposition 3 applies irrespective of whether pollution damages are equally or unequally distributed in the population. However, this does not imply that distributional concerns do not affect the desirability of the tax reform. The distributional impact of pollution determines the optimal Pigouvian pollution tax $\left(q=q^{P}\right)$, and thereby the desirability of the environmental tax reform. Proposition 3 once more reveals that one should be careful to conclude that the regressive incidence of pollution taxes determines the desirability of green tax reforms.

Klenert and Mattauch (2016), Klenert et al. (2016), and Aubert and Chiroleu-Assouline (2017) analyse the environmental and distributional consequences of green tax reforms under different assumptions regarding the recycling of tax revenue via the income tax. They show that a double dividend of a better environment and more income redistribution may exist under some recycling schedules for the income tax, but not under others. These papers might give the impression that the distributional incidence of pollution taxes is important to judge the desirability of green tax reforms. However, this impression is misleading, since all papers employ Stone-Geary utility functions that belong to the Gorman polar class. Proposition 2 shows that in this case optimal pollution taxes should not be aimed at income redistribution. Moreover, Proposition 3 demonstrates that a double dividend of a better environment and more income redistribution always exists under the specific tax reform being analysed (a decrease in the tax rate jointly with an increase in the demogrant). Klenert and Mattauch (2016), Klenert et al. (2016), and Aubert and Chiroleu-Assouline (2017) do not analyse this reform, which explains why they do not unambiguously find a double dividend of a better environment and more income redistribution.

\section{Simulations of optimal climate and redistribution policies and tax reform}

To what extent do non-Gorman polar forms for preferences affect the optimal pollution tax and to what extent does it differ from the Pigouvian tax? To illustrate our main theoretical findings, this section presents simulations of optimal pollution taxes and redistributive income taxes for two different types of demand systems. In Section 6.1 we formally analyse the behaviour of the demand for polluting goods in the Linear Expenditure System (LES) and the PIGLOG demand system. The LES is based on StoneGeary preferences that are of the Gorman polar form and features linear Engel curves. In contrast, the PIGLOG system is not of the Gorman polar form, and features empirically more plausible non-linear Engel curves (Banks et al., 1997). Section 6.2 discusses the calibration of our demand systems to empirical estimates for fuel demand of Banks et al. (1997). Sections 6.3 and 6.4 give the benchmark and various sensitivity runs for the optimal tax system under the LES and PIGLOG demand system, 
respectively.

\subsection{LES and PIGLOG demand systems}

In applied econometric studies, demand functions for energy and other commodities are usually estimated with flexible demand systems based on price-independent generalised linear (PIGL) preferences (Muellbauer, 1976), which contain PIGLOG, translog and AIDS preferences as special cases (e.g., Deaton and Muellbauer, 1980). ${ }^{24}$ Although the Gorman polar form is a limiting case of PIGL preferences, PIGLOG, translog or AIDS preferences do not satisfy the Gorman polar form. ${ }^{25}$ These latter demand systems satisfy the axioms of order and permit aggregation over consumers without demanding parallel linear Engel curves.

In our application we assume that utility is quasi-linear, utility from clean and dirty goods is separable from leisure, and that the Frisch elasticity of labour supply is constant and denoted (as in Corollary 1) by $\vartheta$. The utility function of individual $n$ is thus $u_{n}=\mathrm{h}\left(c_{n}, b_{n}\right)-l_{n}{ }^{1+1 / \vartheta} /(1+1 / \vartheta), \vartheta>0$, which implies that there are no income effects in labour supply if $h(\cdot)$ is linearly homogeneous. We employ two specifications of sub-utility $\mathrm{h}\left(c_{n}, b_{n}\right)$. The first one is the Stone-Geary utility function, $\mathrm{h}\left(c_{n}, b_{n}-\bar{b}\right)=\left(c_{n} /(1-a)\right)^{1-a}\left(\left(b_{n}-\bar{b}\right) / a\right)^{a}, 0<a<1$, where $\bar{b}$ is the subsistence level for the consumption of polluting goods. This yields the Linear Expenditure System (LES) discussed above with the budget shares, and (un)compensated labour supplies given by:

$$
\begin{aligned}
& \frac{(1+q) b_{n}}{m_{n}}=a+(1-a)(1+q) \bar{b} / m_{n}, \frac{c_{n}}{m_{n}}=(1-a)\left(1-(1+q) \bar{b} / m_{n}\right), 0<a<1, \bar{b}>0, \\
& l_{n}=l_{n}^{c}=\left((1-t) n /(1+q)^{a}\right)^{\vartheta} .
\end{aligned}
$$

Our second specification employs PIGLOG preferences that are characterised by the following expenditure function:

$$
\mathrm{m}\left(h_{n}, q\right)=\Theta(q) \Pi(q)^{\ln \left(h_{n}\right)},
$$

where $m_{n}=\mathrm{m}\left(h_{n}, q\right)=c_{n}+(1+q) b_{n}$ is the minimal expenditure required to reach utility level $h_{n}$ for individual $n$ if the pollution tax is $q$. PIGLOG preferences have no neatly defined direct utility function.

Denote by $\Theta(q) \equiv(1+q)^{\chi_{0}}$ and $\ln (\Pi(q)) \equiv(1+q)^{-\chi_{1}}$ with $\chi_{0}>0$ and $\chi_{1}>0$, then Shephard's lemma gives the compensated demand function: $b_{n}=\partial \mathrm{m}\left(h_{n}, q\right) / \partial q=\left(\chi_{0}-\chi_{1}(1+q)^{-\chi_{1}} \ln \left(h_{n}\right)\right) m_{n} /(1+q)$.

\footnotetext{
${ }^{24}$ Bohi and Zimmerman (1984) give a survey of econometric estimates of energy demand functions.

${ }^{25}$ Empirical energy demand studies often use flexible functional forms based on, for example, translog functional forms (e.g., Berndt and Wood, 1975; Pindyck, 1979) or Diewert's generalised Cobb-Douglas functional forms (e.g., Magnus, 1979) to estimate energy demand. These are not of the Gorman polar form either.
} 
Hence, with PIGLOG preferences the budget shares of dirty and clean goods are given by:

$$
\frac{(1+q) b_{n}}{m_{n}}=\chi_{0}-\chi_{1} \ln \left(\frac{m_{n}}{(1+q)^{\chi_{0}}}\right), \frac{c_{n}}{m_{n}}=1-\chi_{0}+\chi_{1} \ln \left(\frac{m_{n}}{(1+q)^{\chi_{0}}}\right) .
$$

By inverting $\ln \left(h_{n}\right)=(1+q)^{\chi_{1}}\left(\ln \left(m_{n}\right)-\chi_{0} \ln (1+q)\right)$, we obtain the indirect utility function for the PIGLOG system: $v\left(q, m_{n}\right)=\left(m_{n} /(1+q)^{\chi_{0}}\right)^{(1+q)^{\chi_{1}}}$. The corresponding expenditure function is thus given by: $m\left(h_{n}, q\right)=(1+q)^{\chi_{0}} h_{n}^{-(1+q)^{\chi_{1}}}$. Maximising utility $v\left(q, m_{n}\right)=\left(\frac{(1-t) n l_{n}+s}{(1+q)^{\chi_{0}}}\right)^{(1+q)^{\chi_{1}}}-\frac{l_{n}^{1+1 / \vartheta}}{1+1 / \vartheta}$ gives the uncompensated labour supply function with PIGLOG preferences:

$$
l_{n}=\left(\frac{(1+q)^{\chi_{1}}(1-t) n h_{n}}{(1-t) n l_{n}+s}\right)^{\vartheta} .
$$

Labour supply is thus an increasing function of the pollution tax under PIGLOG demand (i.e., $\varepsilon_{l q}>0$ ), but a negative function of the pollution tax under LES demand. This implies that polluting goods and leisure are complements under PIGLOG preferences.

In both demand systems polluting goods are necessities and clean goods are luxuries. The Engel curves of the LES (18) are linear. In contrast, in the PIGLOG system (18'), the Engel curves are nonlinear. PIGLOG preferences are thus not of the Gorman polar form and Proposition 2 does not apply. ${ }^{26}$ The budget share of polluting goods (18) and $\left(18^{\prime}\right)$ rises in the pollution tax for both demand systems. Dirty goods are normal goods under LES demand at any level of income, but become inferior goods at high levels of income under PIGLOG demand.

\subsection{Calibration}

We calibrate both demand systems to the same data. Figure 1.B of Banks et al. (1997) plots the budget share of domestic fossil fuel in the United Kingdom as a negative linear function of the logarithm of fuel expenditure. This budget share varies linearly from 0.1 at $\ln$ (expenditure) $=4.3$ down to 0.04 at $\ln ($ expenditure $)=5.5$. Consequently, the budget share of polluting goods declines, but the budget share of clean goods rises in the logarithm of total expenditure. For our illustration we let domestic fossil fuel correspond to 'polluting' goods and we lump together food, clothing, alcohol and other consumer items as

\footnotetext{
${ }^{26}$ One non-parametric analysis of a long time series of consumer expenditure patterns in the U.K. suggests that Engel curves are quadratic in the logarithm of expenditure (Banks et al., 1997). This corresponds to so-called QUAIDS demand systems, which generalises PIGLOG and AIDS demand systems, and are of the non-Gorman polar form. Not taking account of this type of Engel curvature in clothing and alcohol consumption induces important distortions in the patterns of welfare losses associated with a tax increase, but this curvature does not appear to be relevant for fuel or foods.
} 
'clean' goods. This gives PIGLOG estimates of $\chi_{0}=0.315$ and $\chi_{1}=0.05$.

As shown in Figure 2, we approximate the LES system in eq. (18) by fitting a least squares regression $b_{n}=(1-a) \bar{b}+a m_{n}$ (dashed line) to the data generated by the PIGLOG system (solid line). This gives $a=0.0146$ and $\bar{b}=7.098\left(\mathrm{R}^{2}=0.77\right)$. Figure 2 shows that estimated demand for polluting goods with the LES demand system is too high for low and high levels of expenditures and too low for medium levels of expenditures.

Figure 2 - Calibration of LES system to data generated by PIGLOG system

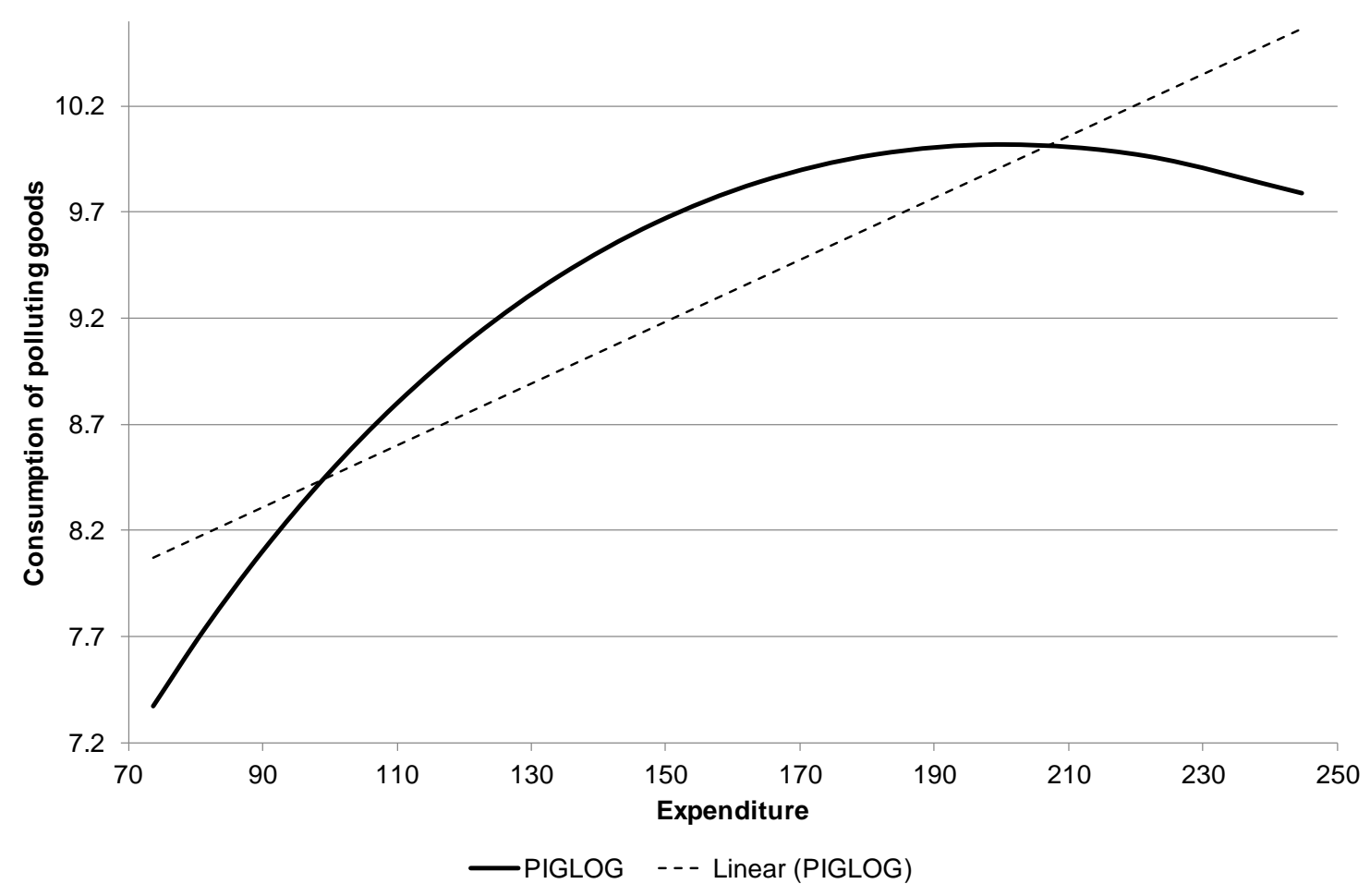

Armed with the calibrated eqs. (18)-(19) and $\left(18^{\prime}\right)-\left(19^{\prime}\right)$, we investigate whether there is a significant wedge between the optimal pollution tax and the Pigouvian tax in the PIGLOG demand system. If there is a substantial wedge, then one should be careful in drawing policy conclusions from estimates based on the LES demand system, which assume Gorman polar form preferences, and - by definition - feature no wedge between the optimal and the Pigouvian pollution tax.

The simulations also require information on the wage elasticity of labour supply, a parameterisation of the social welfare weights, a description of the skill distribution, and a parameterisation of the pollution damage function. All details of our calibration are summarised in Table 1 . 
We assume a (un)compensated wage elasticity of labour supply equal to $\vartheta=0.25$, which is consistent with the estimates reported and discussed in Blundell and MaCurdy (1999) and Meghir and Phillips (2010). We also perform a sensitivity analysis with $\vartheta=0.35$.

Table 1 - Parameters calibration (robustness checks in parentheses)

Parameters PIGLOG utility

Parameters LES utility

Wage elasticity of labour supply

Parameters social welfare weights

Pre-tax income distribution

Public revenue requirement

Marginal pollution damages

Rate at which pollution damages decline with ability

$$
\begin{aligned}
& \chi_{0}=0.315, \chi_{1}=0.05 \\
& a=0.0146, \bar{b}=7.098 \\
& \vartheta=0.25(\vartheta=0.35) \\
& \psi=4(\psi=2), \psi_{0}=27.68 \times 10^{6} \\
& \varpi=0.4(\varpi=0.8), \bar{n}=92.3 \\
& R=50(R=30) \\
& \Xi_{0}=0.1\left(\Xi_{0}=0.2\right) \\
& \Xi_{1}=0\left(\Xi_{1}=1\right)
\end{aligned}
$$

We assume exponentially declining Pareto weights: $\omega_{n}=\psi_{0} n^{-\psi}$, with $\psi_{0}=27.68 \times 10^{6}$ such that $\mathrm{E}\left[\omega_{n}\right]=1 . \psi$ corresponds to the coefficient of relative inequality aversion (cf. Atkinson, 1970). ${ }^{27} \mathrm{We}$ assume a rather redistributive government by setting $\psi=4$. We also consider a sensitivity exercise with a lower degree of inequality aversion of $\psi=2$. Since we assumed quasi-linear utility, the private marginal utility of income is constant. Consequently, only the government's aversion to inequality generates a motive for income redistribution. The public revenue requirement is $R=50$, but we also consider a lower requirement of $R=30$ as a sensitivity exercise.

We use the lognormal (or Galton) distribution to describe the distribution of earning abilities of individuals. Hence, $\ln (n)$ is normally distributed with mean $\ln (\bar{n})$ and standard deviation $\varpi>0 .{ }^{28}$ We set $\varpi=0.4$ (cf., Stern, 1976). Mean labour productivity is calibrated so that $\mathrm{E}[n]=100$ without government intervention: $\bar{n}=100 / \exp \left(0.5 \varpi^{2}\right)=92.3$. This yields $\mathrm{E}[\ln (n)]=4.525$. As a sensitivity check, we also examine the effects of a higher dispersion of incomes by setting $\varpi=0.8$.

\footnotetext{
${ }^{27}$ A more conventional social welfare function weights by utility rather than ability, so that $\omega_{n}=v_{n}^{-\psi}$. Given that the private marginal utility of income is constant, assuming exogenous social welfare weights is without loss of generality.

${ }^{28}$ More realistic would be to append a Pareto tail to the log-normal distribution to capture the upper end of the earnings distribution (e.g., Atkinson et al., 2011). However, we abstract from this extension. Since we analyse linear income taxes, doing so would not bring any essential insights for our purposes.
} 
Finally, let $\mathrm{D}(b, n)=\Xi_{0} b(\mathrm{E}[n] / n)^{\Xi_{1}}$ be the function describing pollution damages, where the coefficient $\Xi_{1}$ indicates the extent to which pollution damages vary with the ability of individuals. For our benchmark we suppose $\Xi_{0}=0.1$ and that the pollution weights are the same for all individuals, i.e., $\Xi_{1}$ $=0$ As sensitivity exercises, we also explore the case where pollution damages are double the size, i.e., $\Xi_{0}=0.1$, and where the incidence of pollution falls disproportionally on the poorest individuals, i.e., $\Xi_{1}=$ 1. The Pigouvian pollution tax in eq. (7) or eq. (13) boils down to $q^{P}=\Xi_{0} \int_{0}^{\infty} \omega_{n}(\mathrm{E}[n] / n)^{\Xi_{1}} \mathrm{f}(n) \mathrm{d} n / \lambda$, which simplifies to $q^{P}=\Xi_{0} / \lambda$ if $\Xi_{1}=0$.

\subsection{Optimal taxation with LES demand}

Table 2 gives the results if commodity demands follow from the LES for the baseline and various sensitivity checks. The main finding is that the pollution tax is always set at its Pigouvian level. As prescribed by Corollary 1, we know that for LES demand the optimal pollution tax is directed exclusively at internalising pollution externalities, and not at income redistribution, since $q=q^{P}=\mathrm{p}(q) \mathrm{D}^{\prime}(b)$. The linear income tax redistributes income with a positive marginal marginal tax rate and positive lump-sum transfers. The income tax is progressive, since the marginal tax rate always exceeds the average tax rate. The numerical simulations confirm that higher inequality aversion, more ex-ante inequality, a higher labour-supply elasticity, or a larger public revenue requirement do not change the optimal pollution tax. The income tax system does adjust, however.

Table 2 - Optimal pollution and income tax system with LES demand

\begin{tabular}{lccccccc}
\hline \hline & Baseline & $\begin{array}{l}\text { Less } \\
\text { inequality } \\
\text { aversion } \\
(\psi=2)\end{array}$ & $\begin{array}{l}\text { More } \\
\text { income } \\
\text { inequality } \\
(\varpi=0.8)\end{array}$ & $\begin{array}{l}\text { Larger } \\
\text { pollution } \\
\text { damages } \\
\left(\Xi_{0}=0.2\right)\end{array}$ & $\begin{array}{l}\text { Regressive } \\
\text { pollution } \\
\text { incidence } \\
\left(\Xi_{1}=1\right)\end{array}$ & $\begin{array}{l}\text { Higher } \\
\text { labour } \\
\text { elasticity } \\
(\vartheta=0.35)\end{array}$ & $\begin{array}{l}\text { Lower } \\
\text { public } \\
\text { revenue } \\
(R=30)\end{array}$ \\
\hline Marginal tax rate $t(\%)$ & 65.9 & 55.7 & 77.9 & 65.9 & 65.9 & 59.4 & 65.9 \\
Income transfer $s$ & 120 & 103 & 154 & 121 & 121 & 185 & 140 \\
Av. income tax $(\%)$ & 19.1 & 17.9 & 18.8 & 18.8 & 18.8 & 12.4 & 11.3 \\
Pollution tax $q(\%)$ & 10.0 & 10.0 & 10.0 & 20.1 & 18.3 & 10.0 & 10.0 \\
Distr. char. $l \xi_{l}$ & 0.48 & 0.31 & 0.88 & 0.48 & 0.48 & 0.51 & 0.48 \\
Distr. char. $b \xi_{b}$ & 0.06 & 0.05 & 0.07 & 0.05 & 0.06 & 0.09 & 0.06 \\
Av. labour supply & 2.40 & 2.56 & 2.07 & 2.39 & 2.40 & 3.62 & 2.40 \\
Pollution $b$ & 9.75 & 9.98 & 9.80 & 9.53 & 9.56 & 11.58 & 10.01 \\
\hline
\end{tabular}


Halving inequality aversion $(\psi=2)$ reduces the demand for redistribution and thus leads to a lower income tax rate and a lower lump-sum transfer. Consequently, there are fewer income tax distortions and more economic activity and pollution. The pollution tax does not adjust to fight the increase in pollution. More pre-tax income inequality ( $\varpi=0.8$ ) has the opposite effects. Aggregate pollution increases despite the drop in output because there are now more poor people that spend relatively more on polluting goods. Again, the pollution tax does not react to the rise in total pollution.

If pollution damages double $\left(\Xi_{0}=0.2\right)$, the optimal pollution tax roughly doubles, but the income tax rate and the lump-sum transfer hardly change. Aggregate economic activity is not much affected, but aggregate pollution falls due to the higher pollution tax.

A higher wage elasticity of labour supply $(\vartheta=0.35)$ raises the distortions of income taxation and thus induces a lower income tax rate (the Ramsey motive), since the government faces a more severe trade-off between equity and efficiency. Therefore, it sacrifices on income redistribution by lowering marginal income tax rates. As a result, aggregate economic activity expands and pollution increases. A higher elasticity also raises the lump-sum transfer. The main reason is that average labour supply increases with more than 50 percent. This is mainly a mechanical increase in labour supply due to changing the utility function, and only partly a behavioural response. ${ }^{29}$ As always with the Gorman polar preferences, the optimal pollution tax does not respond to this additional pollution.

A smaller public revenue requirement $(R=30)$ leaves the income tax rate (and the pollution tax) unaffected and, due to the assumption of quasi-linearity, leads to a one-to-one increase in lump-sum transfers. Economic activity is unaffected, but higher net incomes lead to more spending, and thus to more aggregate pollution.

To sum up, with LES demand we confirm that the government does not use the pollution tax for redistribution and sets the optimal pollution tax at the Pigouvian level even if the poor spend relatively more on polluting goods.

\subsection{Optimal taxation with PIGLOG demand}

Table 3 presents the results for PIGLOG demand. Comparing the benchmark outcome with that for the LES case in Table 2, the key distinguishing feature is that the optimal pollution tax now differs from the Pigouvian tax due to the departure from Gorman polar preferences. The benchmark optimal pollution tax is 0.8 percentage point lower than the Pigouvian tax. With PIGLOG preferences, the government thus

\footnotetext{
${ }^{29}$ If taxes decline from 66 to $59 \%$, and the labour supply elasticity is 0.35 , average labour supply approximately increases with $\mathrm{d} l / l=-\varepsilon_{l t} \times \mathrm{d} t /(1-t)=7$ percent. This is a fraction of the increase in labour supply in the simulations.
} 
also employs the pollution tax to redistribute incomes and to alleviate labour-market distortions caused by the income tax.

To gain more intuition for the gap between the optimal pollution tax and the Pigouvian tax, we can rewrite eq. (8) in Proposition 1 as:

(21) $\frac{q-q^{P}}{1+q} \underbrace{\left(\frac{-\overline{\beta \varepsilon_{b q}}}{\bar{\beta}}\right)}_{+}=\xi_{b}+\underbrace{\frac{t}{(1-t)} \frac{\overline{\varepsilon_{l q}}}{-\overline{\varepsilon_{l t}} \bar{\beta}}}_{+}$,

where we have signed the various terms of the optimal pollution tax for the PIGLOG case, based on our simulations. The left-hand side of eq. (21) gives the marginal deadweight loss of distorting polluting goods demand away from the Pigouvian level. The government optimally sets a larger (smaller) gap between the pollution tax and the Pigouvian tax, the less (more) elastic is the demand for polluting goods is, i.e. if $-\overline{\beta \varepsilon_{b q}} / \bar{\beta}$ is smaller (larger) - ceteris paribus benefits of doing this the right-hand side of eq. (21). Intuitively, deviations from the Pigouvian tax generate smaller (larger) distortions in demand for polluting goods if the demand for polluting goods is less (more) elastic.

Table 3 - Optimal pollution and income tax system with PIGLOG demand

\begin{tabular}{lccccccc}
\hline \hline & Baseline & $\begin{array}{l}\text { Less } \\
\text { inequality } \\
\text { aversion } \\
(\psi=2)\end{array}$ & $\begin{array}{l}\text { More } \\
\text { income } \\
\text { inequality } \\
(\varpi=0.8)\end{array}$ & $\begin{array}{l}\text { Larger } \\
\text { pollution } \\
\text { damages } \\
\left(\Xi_{0}=0.2\right)\end{array}$ & $\begin{array}{l}\text { Regressive } \\
\text { pollution } \\
\text { incidence } \\
\left(\Xi_{1}=1\right)\end{array}$ & $\begin{array}{l}\text { Higher } \\
\text { labour } \\
\text { elasticity } \\
(\vartheta=0.35)\end{array}$ & $\begin{array}{l}\text { Lower } \\
\text { public } \\
\text { revenue } \\
(R=30)\end{array}$ \\
\hline Marginal tax rate $t(\%)$ & 65.9 & 55.6 & 77.8 & 65.8 & 65.8 & 59.3 & 65.9 \\
Income transfer $s$ & 120 & 103 & 154 & 120 & 120 & 185 & 140 \\
Av. income tax $(\%)$ & 19.2 & 18.0 & 18.8 & 18.9 & 19.0 & 12.5 & 11.4 \\
Pollution tax $q(\%)$ & 9.2 & 8.3 & 12.0 & 16.6 & 15.3 & 9.9 & 8.8 \\
Pigouvian tax $q^{P}(\%)$ & 10.0 & 10.0 & 10.0 & 20.0 & 18.2 & 10.0 & 10.0 \\
Distr. char. $l \xi_{l}$ & 0.48 & 0.31 & 0.88 & 0.48 & 0.48 & 0.51 & 0.48 \\
Distr. char. $b \xi_{b}$ & -0.01 & -0.03 & -0.03 & -0.01 & -0.01 & -0.30 & -0.03 \\
Av. labour supply & 2.40 & 2.56 & 2.07 & 2.40 & 2.40 & 3.73 & 2.40 \\
Pollution $b$ & 8.931 & 8.767 & 8.465 & 8.365 & 8.461 & 6.601 & 8.906 \\
\hline
\end{tabular}

The right-hand side of eq. (21) gives the benefits in terms of redistribution or lower labour market distortions of setting pollution taxes at non-Pigouvian rates. First, with PIGLOG preferences, polluting goods can be inferior. In particular, expenditure on dirty goods first rises and then declines with income, as also shown in Figure 2. In our simulations, the distributional characteristic for polluting goods $\xi_{b}$ is 
negative. Hence, the inferiority of polluting goods at high levels of income dominates the normality of polluting goods at lower incomes. Consequently, the government likes to lower the tax on polluting goods below the Pigouvian level for redistributional reasons - ceteris paribus. Second, polluting goods and leisure are found to be (strong) complements with PIGLOG preferences, since labour supply increases if we raise the pollution tax, i.e. $\varepsilon_{l q}>0$, which follows from eq. (21). Consequently, the government likes to set pollution taxes above the Pigouvian rate to alleviate the distortions of the income tax on labour supply - ceteris paribus. This is the Corlett and Hague (1953) motive for differential commodity taxation. The gap between the optimal pollution tax and the Pigouvian tax thus depends on these two opposing effects and can be positive or negative. This explains why in Table 3 the optimal pollution tax sometimes is below and at other times is above the Pigouvian tax.

Cutting income inequality aversion in half $(\psi=2)$ implies that the government has a smaller desire to redistribute income. Consequently, the income tax system becomes less progressive due to a lowering of the income tax rate and the lump-sum transfer. The optimal pollution tax slightly decreases for two reasons. First, less redistribution implies that net incomes of high-income individuals increase for whom polluting goods are inferior - while net incomes of low-income individuals decrease - for whom polluting goods are normal. On average polluting goods are thus more inferior, so that the distributional characteristic of polluting goods decreases, and optimal pollution taxes should be lowered. Second, labour market distortions are less severe if labour taxes are lower. Consequently, the optimal tax on polluting goods falls, since there is less reason to tax polluting goods to alleviate labour market distortions.

Doubling pre-tax inequality $(\varpi=0.8)$ makes the optimal income tax system more progressive. Intuitively, the distributional characteristic of labour income increases substantially and a higher income tax rate is optimal. The optimal pollution tax is raised above the Pigouvian pollution tax, for two reasons. First, larger pre-tax inequality lowers the distributional characteristic of the polluting good, because it becomes more inferior - see also previous paragraph where we discussed the effect of larger after-tax inequality. Hence, larger pre-tax inequality tends to lower the pollution tax. Second, labour-market distortions increase if optimal labour taxes are set at higher rate. For that reason, the optimal tax on polluting goods should increase, since taxing polluting goods has larger benefits in terms of reducing labour-market distortions. The last effect dominates, so that optimal pollution taxes are driven above the Pigouvian rates. Doubling marginal pollution damages $\left(\Xi_{0}=0.2\right)$ leads to a doubling of the Pigouvian tax, but the optimal pollution tax falls relatively more below the Pigouvian tax compared to the baseline. If global warming damages hit the poor relatively more $\left(\Xi_{1}=1\right)$, the equity-weighted Pigouvian tax increases from 10 percent to 18.2 percent, since the government cares relatively more about the poor more than about the rich. As with doubling marginal damages, the gap between the optimal pollution tax and 
the Pigouvian increases. Aggregate economic activity is hardly affected in both cases compared to the baseline, but aggregate pollution falls substantially.

A higher wage elasticity of labour supply $(\vartheta=0.35)$ increases the efficiency loss from income taxation and thus lowers the optimal income tax rate. A higher elasticity also raises the lump-sum transfer, because average incomes increase due to a near doubling of labour supply, which is mainly the mechanical result of changing the utility function. The pollution tax increases compared to the baseline, but still slightly below the Pigouvian rate. Intuitively, a higher elasticity of labour supply indicates that pollution taxes should be increased to reduce larger labour-market distortions. On the other hand, a higher distributional characteristic of polluting goods - because polluting goods have become more inferior on average - calls for lower pollution taxes to redistribute more income. The net effect is that pollution taxes increase compared to the baseline.

Whether optimal corrective taxes should substantially deviate from Pigouvian taxes is thus an empirical question. The gap between the optimal corrective tax and the Pigouvian tax may be negative or positive, depending on whether polluting goods are normal or inferior and whether they are stronger complements to leisure than clean goods are. Setting the corrective tax at the Pigouvian rate is a useful first approximation and doing so is certainly better than setting no pollution tax at all. However, our simulations also demonstrate that one has to be careful in drawing policy conclusions if preferences are not of the Gorman polar form. If the data for the demand for polluting goods in fact suggest non-Gorman polar preferences, then setting pollution taxes at the Pigouvian rate can be misleading.

\section{Robustness}

This section discusses how our results are affected if some important assumptions in our model are relaxed. First, we discuss the implications of constraining the government instruments to exclude nonindividualised lump-sum transfers. Second, we analyse the consequences of expanding the government instrument set by allowing for non-linear taxes. Third, we verify whether our results can be generalised to production externalities. Fourth, we discuss the implications of general equilibrium effects.

\subsection{Constraints on lump-sum transfers}

The double dividend literature analyses corrective taxes in models with homogenous agents, where nonindividualised lump-sum transfers are not available or are fixed at levels before pollution was a concern (e.g., Sandmo, 1975; Bovenberg and De Mooij, 1994; Bovenberg and van der Ploeg, 1994). The government has then only two instruments - the pollution tax and the income tax - to serve three goals: revenue raising, income redistribution and correcting externalities. If non-individualised lump-sum transfers are no longer available, the government thus loses its non-distortionary marginal source of 
public finance so that both the distortionary income and pollution taxes are needed to raise government revenue in the most efficient manner. Consequently, the marginal cost of public funds is no longer equal to one and governments face a trade-off between correcting externalities and redistributing income (Jacobs and De Mooij, 2015, Proposition 3). Whereas ruling out individualised lump-sum transfers is necessary to obtain a second-best problem in representative-agent models, such ad hoc constraints on the government instrument set are no longer needed if heterogeneous agents are allowed for (as this and other papers have shown). Moreover, although one might have objections to allowing for lump-sum taxes, it is not clear politically why the government cannot provide its citizens with lump-sum transfers. We have shown that the optimal redistributive tax system generally features a positive lump-sum transfer and positive marginal tax rates. Also in practice, governments do have access to a non-distortionary marginal source of finance, since most tax-benefit systems feature a general tax exemption/credit or a guaranteed minimum income, which can be cut at the margin. Clearly, more research is needed to explain the deeper political reasons why certain policy instruments can and why others cannot be used.

\subsection{Non-linear income taxation}

Our paper relates to a number of other papers in the literature on optimal corrective taxation and optimal income redistribution under non-linear, Mirrleesian labour taxes. Cremer et al. (1998, 2003), Micheletto (2008) and Jacobs and De Mooij (2015) show that, if preferences are weakly separable between labour on the one hand and private commodities and environmental quality on the other, and sub-utility over these commodities is identical across individuals, optimal pollution taxes should be set at Pigouvian rates and the structure of the optimal nonlinear income tax should be the same as in the absence of pollution. ${ }^{30}$ Hence, if non-linear income taxes can be levied, linear Engel curves are no longer necessary to find no redistributive role for pollution taxes. Moreover, if the government optimises a non-linear income tax distribution-neutral green tax reforms are always feasible under weakly separable preferences, even if preferences are not of the Gorman polar form (Kaplow, 2012). However, in practice, a fully non-linear income tax system might be difficult to implement. Indeed, in the real world governments generally levy linear or piecewise linear income taxes, so that our analysis of linear instruments is relevant.

Cremer and Gahvari (2001) and Cremer et al. (2003) demonstrate that if preferences for polluting goods are heterogeneous, corrective taxes need to take into account the distributional concerns as well even if income taxes are non-linear. In that case, pollution taxes complement the non-linear income tax to redistribute income, as in our analysis with linear income taxes with non-Gorman polar preferences. This argument for differential commodity taxation under heterogeneous preferences goes back to Mirrlees

\footnotetext{
${ }^{30}$ We generalise Corollary 1 of Jacobs and De Mooij (2015) for the general class of Gorman polar utility functions.
} 
(1976) and Saez (2002) who show that governments should use commodity taxes for income redistribution, besides non-linear income taxes, if individual preferences for commodities are heterogeneous.

\subsection{Production externalities}

Our results continue to hold in slightly modified form in the case where pollution externalities do not enter the utility function, but the production function. Suppose that there is a representative firm that maximises profits using a constant-returns-to-scale production technology with aggregate labour $L \equiv \int_{0}^{\infty} n l_{n} \mathrm{f}(n) \mathrm{d} n$ as its only input. The production function is designated by $Y=A(b) L$, where labour productivity $A$ depends negatively on aggregate pollution $b$, i.e., $A^{\prime}(b)<0$. Firms take aggregate pollution $b$ as given. Profit maximisation implies that the wage rate per efficiency unit of labour is given by $w=$ $A(b)$, so that labour demand is perfectly elastic at the wage rate $w$. The individual now maximises $\mathrm{u}\left(c_{n}, b_{n}, 1-l_{n}\right)$ subject to the household budget constraint $c_{n}+(1+q) b_{n}=(1-t) A(b) n l_{n}+s$. As a result, environmental damages enter indirect utility $\mathrm{v}(t, q, s, b, n)$ via the wage rate per efficiency unit of labour $A(b)$. Appendix F derives that the optimal tax formulae of Proposition 1 apply if we redefine the social welfare $\quad$ weights $g_{n}^{*} \equiv g_{n}+t A(b) n \frac{\partial l_{n}}{\partial s}+\left(q-q^{P}\right) \frac{\partial b_{n}}{\partial s}$ and $\quad$ expenditure $\quad$ share $\quad$ of $\beta_{n} \equiv \frac{(1+q) b_{n}}{(1-t) A(b) n l_{n}}$. Moreover, the Pigouvian tax under production externalities is modified to:

$$
q^{P} \equiv \frac{\mu}{\lambda}=-A^{\prime}(b) \int_{0}^{\infty} n l_{n} \mathrm{f}(n) \mathrm{d} n=-\frac{A^{\prime}(b)}{A(b)} Y .
$$

The Pigouvian tax in case of production externalities requires no equity weighting of pollution damages because production externalities affect all wages of workers symmetrically. There is otherwise no difference compared to the model with consumption externalities.

If one were to allow for multiple production sectors, each causing different externalities, production efficiency would be obtained, also in second-best settings with distortionary taxation, provided the government can tax or subsidise each sector (Cremer and Gahvari, 2001). Furthermore, this also implies that abatement investments, reducing the aggregate amount of pollution, should be efficient. Intuitively, investments in abatement are intermediate goods in the production of environmental quality. If production of environmental quality should be efficient, then investment in abatement should also satisfy first-best principles in second-best settings (Diamond and Mirrees, 1971a).

\subsection{General equilibrium}

We have abstracted from general-equilibrium effects on factor prices, which could affect the 
distributional consequences of taxes on income and pollution (see, for example, Fullerton and Heutel, 2007; Fullerton and Monti, 2013). However, the partial-equilibrium assumption does not affect our results, because the optimal tax formulae are the same in general as in partial equilibrium if Diamond and Mirrlees' (1971a, b) production efficiency theorem applies. The Diamond-Mirrlees production efficiency theorem rests on the following two premises. First, production takes place under constant returns to scale or, if production takes place under decreasing returns to scale, profits should be fully taxed away. ${ }^{31}$ Second, all transactions between firms and households should be verifiable so that consumer prices can be set independently from producer prices. In our model, and all models that derive from Mirrlees (1971), the government cannot observe individual wage rates. However, if all labour inputs are perfect substitutes in production, the wage rate per efficiency unit of labour is equalised across individuals. In that case, the government can levy a tax on the entire wage bill and does not need to verify individual wage rates.

This second condition for production efficiency does not hold if labour types are imperfect substitutes in production and the government cannot tax/subsidise each occupation separately. In that case, distributional effects originating from general-equilibrium effects on factor or commodity prices might become relevant for evaluating green tax reforms. For example, Fullerton and Monti (2013) analyse pollution taxes in a general-equilibrium model with high- and low-skilled occupations. Their simulations show that an increase in pollution taxes, while rebating all revenue to low-skilled labour does not prevent a reduction in their overall net wage, since pollution taxes reduce their before-tax wage rate. Similarly, Gahvari (2014) analyses optimal non-linear taxation with endogenous wages. Since the government cannot condition the tax schedule on the occupation of the individual, the second condition for production efficiency does not hold. Consequently, optimal pollution taxes take into account the general-equilibrium effects on wage rates. ${ }^{32}$ However, if the government has sufficient instruments to tax/subsidise each occupational type separately, for example via education subsidies or occupation-specific tax schedules, the government no longer relies on production distortions to redistribute income, and production efficiency is restored (Scheuer and Werning, 2016). Intuitively, production distortions emerge only if the government lacks the instruments needed to directly redistribute between different occupations.

\footnotetext{
${ }^{31}$ If there is no profit tax, there will be scarcity rents left so that the production efficiency theorem no longer holds and environmental command-and-control regulations have benefits (e.g., Fullerton and Metcalf, 2001).

${ }^{32}$ Chiroleu-Assoline and Fodha (2014) analyse green tax reforms in a very different setup than the standard Mirrleesian optimal tax framework. They study an OLG model with exogenous labour supply (hence labour taxes are lump sum), homogeneous production externalities (rather than heterogeneous consumption externalities), heterogeneous discount rates and wage rates. Labour types are perfect substitutes in production. They also find that Pareto-improving green tax reforms could be feasible with the proper adjustments of the income tax.
} 


\section{Conclusions}

Our main policy implication is that one should be careful to conclude that corrective pollution taxes need to take into account distributional concerns. This paper has shown that - even assuming restrictive, linear instruments - the case for adjusting corrective pollution taxes for distributional concerns fundamentally relies on non-linear Engel curves for polluting goods. With Gorman polar preferences, which include quasi-linear, CES and Stone-Geary preferences as special cases, Engel curves are linear and the optimal corrective pollution tax does not deviate from the Pigouvian level in second-best settings, despite a possible regressive incidence. To illustrate the importance of non-linear Engel curves for the setting of optimal corrective taxes, we simulated our model on an empirically reasonable calibration for fuel demand. We found that optimal corrective taxes can be both higher and lower than the Pigouvian tax depending on whether distributional costs of pollution taxes are higher or whether the government wants to employ pollution taxes to alleviate labour-market distortions. The Pigouvian tax might be a useful first approximation for the optimal pollution tax, especially if distributional goals can be addressed directly by the tax and transfer system. However, one should be careful to draw policy conclusions about the optimal pollution tax if empirical evidence clearly indicates that Engel curves for polluting goods are non-linear and if the tax-benefit system cannot be tailored to fully neutralise the distributional impact of the pollution tax.

\section{References}

Adler, M., D. Anthoff, V. Bosetti, G. Garner, K. Keller and N. Treich (2016). Priority for the worse off and the social cost of carbon, Working Paper No. 6032, CESifo, Munich.

Advani, A., P. Johnson, A. Leicester and G. Stoye (2013). Household energy use in Britain: A distributional analysis, IFS Report R85, Institute for Fiscal Studies, London.

Aigner, R. (2014). Environmental taxation and redistribution concerns, Finanzarchiv, 70, 29, 249-277.

Althor, G., J.E.M. Watson and R.A. Fuller (2016). Global mismatch between greenhouse gas emissions and the burden of climate change, Nature, 6, 20281.

Anthoff, D., C. Hepburn and R.S.J. Tol (2009). Equity weighting and the marginal damage costs of climate change, Ecological Economics, 68, 3, 836-849.

Anthoff, D. and R.S.J. Tol (2010). On international equity weights and national decision making on climate, Journal of Environmental Economics and Management, 60, 1, 14-20.

Atkinson, A.B. (1970). On the measurement of economic inequality, Journal of Economic Theory, 2, 3, 244-263.

Atkinson, A.B. and J.E. Stiglitz (1976). The design of tax structure: Direct versus indirect taxation, Journal of Public Economics, 6, 1-2, 55-75.

Atkinson, A.B., T. Piketty and E. Saez (2011).Top incomes in the long run of history, Journal of Economic Literature, 49, 1, 3-71.

Aubert, D. and M. Chirouleu-Assouline (2017). Environmental tax reform and income distribution with imperfect heterogeneous labour markets, Working Paper No. 6498, CESifo, Munich. 
Banks, J. R. Blundell and A. Lewbel (1997). Quadratic Engel curves and consumer demand, Review of Economics and Statistics, 79, 4, 527-539.

Baumgärtner, S., M.A. Drupp, J.N. Meya, J.M. Munz and M.F. Quaas (2017). Income inequality and willingness to pay for environmental public goods, Journal of Environmental Economics and Management, 85, 35-61.

Berndt, E.R. and D.O. Wood (1975). Technology, prices, and the derived demand for energy, Review of Economics and Statistics, 57, 3, 259-268.

Blundell, R. and T. MaCurdy (1999). Labour supply: a review of alternative approaches, Chapter 27, in: O. Ashenfelter and D. Card (eds.), Handbook of Labour Economics, Volume 3, Elsevier, New York, 1559-1695.

Boadway, R. and J.-F. Tremblay (2008). Pigouvian taxation in a Ramsey world, Asia-Pacific Journal of Accounting and Finance, 183-204.

Bohi, D.R. and M.B. Zimmerman (1984). An update on econometric studies of energy demand behavior, Annual Review of Energy, 9, 105-154.

Boppart, T. (2014). Structural change and the Kaldor facts in a growth model with relative price effects and non-Gorman preferences, Econometrica, 82, 6, 2167-2196.

Bovenberg, A.L. and R.A. De Mooij (1994). Environmental levies and distortionary taxation, American Economic Review, 84, 4, 1085-1089.

Bovenberg, A.L. and F. van der Ploeg (1994). Environmental policy, public finance and the labour market in a second-best world, Journal of Public Economics, 55, 3, 349-390.

Bruce, J.P., H.-S. Yi and E. F. Haites (1995). Climate Change 1995: Economic and Social Dimensions of Climate Change, IPCC and Cambridge University Press, Cambridge, U.K.

Burtraw, D., R. Sweeney and M. Walls (2009). The incidence of U.S. climate policy: alternative uses of revenues from a cap-and-trade auction, National Tax Journal, 62, 3, 497-518.

Chancel, L. and T. Piketty (2015). Carbon and inequality: From Kyoto to Paris, trends in the global inequality of carbon emissions (1998-2013) and prospects for an equitable adaptation fund, Paris School of Economics, Paris.

Chiroleu-Assouline, M. and M. Fodha (2014). From regressive pollution taxes to progressive environmental tax reforms, European Economic Review, 69, July, 126-142.

Comin, D., D Lashkari and M. Mestieri (2015). Structural change with long-run income and price effects, mimeo, Dartmouth University.

Corlett, W.J., and D.C. Hague (1953). Complementarity and the excess burden of taxation, Review of Economic Studies, 21, 1, 21-30.

Crainger, C.A. and C.D. Kohlstad (2010). Who pays a price on carbon?, Environmental and Resource Economics, 46, 3, 359-376.

Crawford, I., M. Keen and S. Smith (2010). Value added tax and excises, Chapter 4, in: S. Adam, T. Besley, R. Blundell, S. Bond, R. Chote, M. Gammie, P. Johnson, G. Myles and J. M. Poterba (eds.). The Mirrlees Review. Dimensions of Tax Design, Oxford University Press, Oxford, 275362.

Cremer, H. and F. Gahvari (2001). Second-best taxation of emissions and polluting goods, Journal of Public Economics, 80, 2, 169-197.

Cremer, H., F. Gahvari and N. Ladoux (1998). Externalities and optimal taxation, Journal of Public 
Economics, 70, 3, 343-364.

Cremer, H., F. Gahvari and N. Ladoux (2003). Environmental taxes with heterogeneous consumers: an application to energy consumption in France, Journal of Public Economics, 87, 12, 2791-2815.

Deaton, A.S. (1977). Equity, efficiency, and the structure of indirect taxation, Journal of Public Economics, 8, 3, 299-312.

Deaton, A.S. and J. Muellbauer (1980). An Almost Ideal Demand System, American Economic Review, $70,3,312-326$.

De Palma, A. and R. Lindsey (2004). Congestion pricing with heterogeneous travelers: A general equilibrium welfare analysis, Networks and Spatial Economics, 4, 2, 135-160.

Diamond, P.A. (1975). A many-person Ramsey rule, Journal of Public Economics, 4, 4, 335-342.

Diamond, P.A. and J. Mirrlees (1971a). Optimal taxation and public production, I: Production efficiency, American Economic Review, 61, 1, 8-27.

Diamond, P.A. and J. Mirrlees (1971b). Optimal taxation and public production II: Tax rules, American Economic Review, 61, 3, 261-278.

Feldstein, M.S. (1972). Distributional equity and the optimal structure of public prices, American Economic Review, 62, 1, 32-36

Flues, F. and A. Thomas (2015), The distributional effects of energy taxes, OECD Taxation Working Papers, No. 23, OECD Publishing, Paris.

Fullerton, D. and G.E. Metcalf (2001). Environmental controls, scarcity rents, and pre-existing distortions, Journal of Public Economics, 80, 2, 249-267.

Fullerton, D. and G. Heutel (2007). The general equilibrium incidence of environmental taxes, Journal of Public Economics, 91, 3-4, 571-591.

Fullerton, D. and H. Monty (2013). Can pollution tax rebates protect low-wage earners?, Journal of Environmental Economics and Management, 66, 3, 539-553.

Fullerton, D., G. Heutel and G.E. Metcalf (2012). Does the indexing of government transfers make carbon pricing progressive?, American Journal of Agricultural Economics, 94, 2, 347-353.

Gahvari, F. (2014). Second-best Pigouvian taxation: A clarification, Environmental and Resource Economics, 59, 4, 525-535.

Gorman, W.M. (1961). On a class of preference fields, Metroeconomica, 13, 2, 53-56.

Hassett, K.A., A. Mathur and G.E. Metcalf (2009). The incidence of a U.S. carbon tax: A lifetime and regional analysis, Energy Journal, 30, 2, 155-178.

Hsiang, S., R. Kopp, A. Jina, J. Rising, M. Delgado, S. Mohan, D.J. Rasmussen, R. Muir-Wood, P. Wilson, M. Oppenheimer, K. Larsen and T. Houser (2017). Estimating economic damages from climate change in the United States, Science, 356, 6345, 1362-1369.

Jacobs, B. (2017), The marginal cost of public funds is one at the optimal tax system, mimeo: Erasmus University Rotterdam.

Jacobs, B. and R. Boadway (2014). Optimal linear commodity taxation under optimal non-linear income taxation, Journal of Public Economics, 117, 1, 201-210.

Jacobs, B. and R.A. de Mooij (2011). Pigou meets Mirrlees: On the irrelevance of tax distortions for the second-best Pigouvian tax, Working Paper No. 3342, CESifo, Munich.

Jacobs, B. and R.A. de Mooij (2015). Pigou meets Mirrlees: On the irrelevance of tax distortions for the second-best Pigouvian tax, Journal of Environmental Economics and Management, 71, May, 90- 
108.

Kaplow, L. (2012). Optimal control of externalities in the presence of income taxation, International Econonomic Review, 53, 2, 487-509.

Klenert, D. and L. Mattauch (2016). How to make a carbon tax reform progressive: The role of subsistence consumption, Economics Letters, 138, January, 100-103.

Klenert, D., G. Schwerhoff, O. Edenhofer and L. Mattauch (2016). Carbon taxation, inequality and Engel's law: The double dividend of redistribution, Environmental and Resource Economics, forthcoming.

Levison, A. (2016). Energy standards are more regressive than taxes: Theory and evidence, Working Paper No. 22956, NBER, Cambridge, Mass.

Magnus, J.R. (1979). Substitution between energy and nonenergy inputs in the Netherlands, 1950-1976, International Economic Review, 20, 2, 465-484.

Mayeres, I. and S. Proost (2001). Marginal tax reform, externalities and income distribution, Journal of Public Economics, 79, 2, 343-363.

Meghir, C. and M. Browning (1991). The effects of male and female supply on commodity demands, Econometrica, 59, 4, 925-951.

Meghir, C. and D. Phillips (2010). Labour supply and taxes, Chapter 3, in: S. Adam, T. Besley, R. Blundell, S. Bond, R. Chote, M. Gammie, P. Johnson, G. Myles and J. M. Poterba (eds.). The Mirrlees Review. Dimensions of Tax Design, Oxford University Press, Oxford, 202-274.

Micheletto, L. (2008). Redistribution and optimal mixed taxation in the presence of consumption externalities, Journal of Public Economics, 92, 10-11, 2262-2274.

Miranda, M.L., S.E. Edwards, M.H. Keating and C.J. Paul (2011). Making the environmental justice grade: The relative burden of air pollution exposure in the United States, International Journal of Environmental Research and Public Health, 8, 6, 1755-1771.

Mirrlees, J. A. (1971). An exploration in the theory of optimum income taxation, Review of Economic Studies, 38, 2, 175-208.

Mirrlees, J. A. (1976). Optimal tax theory: a synthesis, Journal of Public Economics, 6, 4, 327-358.

Mirrlees, J.A. (1978). Social benefit-cost analysis and the distribution of income, World Development, 6, $2,131-138$.

Muellbauer, J. (1976). Community preferences and the representative consumer, Econometrica, 44, 5, 525-543.

Nordhaus, W. (2014). Estimates of the social cost of carbon: Concepts and results from the DICE-2013R model and alternative approaches, Journal of the Association of Environmental and Resource Economists, 1, 1/2, 273-312.

Papageorgiou, C., M. Saam and P. Schulte (2017). Substitution between clean and dirty energy inputs: A macroeconomic perspective, Review of Economics and Statistics, 99, 2, 281-290.

Parry, I., V. Mylonas and N. Vernon (2017). Reforming energy policy in India: Assessing the options, IMF Working Paper WP/17/103, IMF, Washington, D.C.

Pindyck, R.S. (1979). Interfuel substitution and the industrial demand for energy: An international comparison, Review of Economics and Statistics, 61, 2, 169-179.

Pizer, W.A. and S. Sexton (2017). Distributional impacts of energy taxes, Working Paper No. 23318, NBER, Cambridge, Mass. 
Pirttilä, J. and I. Suoniemi (2014). Public provision, commodity demand, and hours of work: An empirical analysis, Scandinavian Journal of Economics, 116, 4, 1044-1067.

Rausch, S., G.E. Metcalf, J.M. Reilly (2011). Distributional aspects of carbon pricing: a general equilibrium approach with micro-data for households, Energy Economics, 33, S1, S20-S33.

Saez, E. (2002). The desirability of commodity taxation under non-linear income taxation and heterogeneous tastes, Journal of Public Economics, 83, 2, 217-230.

Saez, E. and S. Stantcheva (2016). Generalized social marginal welfare weights for optimal tax theory, American Economic Review, 106, 1, 24-45.

Sandmo, A. (1975). Optimal taxation in the presence of externalities, Scandinavian Journal of Economics, 77, 1, 86-98.

Scheuer, F. and I. Werning (2016). Mirrlees meets Diamond-Mirrlees: Simplifying non-linear income taxation, NBER Working Paper No. 22076, Cambridge, Mass: NBER.

Stern, N.H. (1976). On the specification of models of optimal income taxation, Journal of Public Economics, 6, 1-2, 123-162.

Stern, N.H. (2007). The Economics of Climate Change. The Stern Review, Cambridge University Press, Cambridge, U.K.

West, S.E. and R.C. Williams III (2004). Estimates from a consumer demand system: Implications for the incidence of environmental taxes, Journal of Environmental Economic and Management, 47, 3, May, 535-558.

Williams III, R.C. (2006). An estimate of the second-best optimal gasoline tax, considering both efficiency and equity, mimeo, University of Maryland.

\section{Appendix A: Proof of Proposition 1}

The Lagrangian $\Lambda$ for the maximization of social welfare is defined by - where we use aggregate pollution $b$ as a control variable as in Jacobs and De Mooij (2015):

$$
\max _{\{t, q, s, b\}} \Lambda \equiv \int_{0}^{\infty} \omega_{n} \mathrm{v}(t, q, s, b, n)+\lambda\left[t n l_{n}+q b_{n}-s-R\right] \mathrm{f}(n) \mathrm{d} n+\mu\left[b-\int_{0}^{\infty} b_{n} \mathrm{f}(n) \mathrm{d} n\right] .
$$

The following necessary first-order conditions have to hold:

$$
\begin{aligned}
& \frac{\partial \Lambda}{\partial s}=\int_{0}^{\infty}\left[\omega_{n} \eta_{n}-\lambda+\lambda \operatorname{tn} \frac{\partial l_{n}}{\partial s}+(\lambda q-\mu) \frac{\partial b_{n}}{\partial s}\right] \mathrm{f}(n) \mathrm{d} n=0 \\
& \frac{\partial \Lambda}{\partial t}=\int_{0}^{\infty}\left[-\omega_{n} \eta_{n} n l_{n}+\lambda n l_{n}+\lambda t n \frac{\partial l_{n}}{\partial t}+(\lambda q-\mu) \frac{\partial b_{n}}{\partial t}\right] \mathrm{f}(n) \mathrm{d} n=0 \\
& \frac{\partial \Lambda}{\partial q}=\int_{0}^{\infty}\left[-\omega_{n} \eta_{n} b_{n}+\lambda b_{n}+\lambda t n \frac{\partial l_{n}}{\partial q}+(\lambda q-\mu) \frac{\partial b_{n}}{\partial q}\right] \mathrm{f}(n) \mathrm{d} n=0 \\
& \frac{\partial \Lambda}{\partial b}=\int_{0}^{\infty}\left[-\omega_{n} \mathrm{D}_{b}(b, n)+\mu+\lambda t n \frac{\partial l_{n}}{\partial b}+(\lambda q-\mu) \frac{\partial b_{n}}{\partial b}\right] \mathrm{f}(n) \mathrm{d} n=0
\end{aligned}
$$

where we have used Roy's identity in each line to substitute for the derivatives of indirect utility. From the first-order condition for $b$ in (A5), it follows that the Pigouvian pollution tax equals 


$$
q^{P} \equiv \frac{\mu}{\lambda}=\frac{\int_{0}^{\infty} \omega_{n} \mathrm{D}_{b}(b, n) \mathrm{f}(n) \mathrm{d} n}{\lambda}=\int_{0}^{\infty} \frac{\omega_{n} \eta_{n}}{\lambda} \frac{\mathrm{D}_{b}(b, n)}{\eta_{n}} \mathrm{f}(n) \mathrm{d} n=\int_{0}^{\infty} g_{n} \frac{\mathrm{D}_{b}(b, n)}{\eta_{n}} \mathrm{f}(n) \mathrm{d} n .
$$

From the first-order condition for $s$ in (A2) follows that the marginal cost of public funds equals one:

$$
M C P F=1 /\left(\int_{0}^{\infty}\left[g_{n}+t n \partial l_{n} / \partial s+\left(q-q^{P}\right) \partial b_{n} / \partial s\right] \mathrm{f}(n) \mathrm{d} n\right)=1
$$

We simplify the first-order conditions for $t$ and $q$, i.e., (A3) and (A4), in a number of steps. First, we substitute the Slutsky eqs. in eq. (A3) and eq. (A4) and use $q^{P}=\mu / \lambda$ :

$$
\begin{aligned}
& \frac{\partial \Lambda}{\partial t}=\int_{0}^{\infty}\left[-\omega_{n} \eta_{n} n l_{n}+n l_{n}+\lambda t n\left(\frac{\partial l_{n}^{c}}{\partial t}-n l_{n} \frac{\partial l_{n}}{\partial s}\right)+\lambda\left(q-q^{P}\right)\left(\frac{\partial b_{n}^{c}}{\partial t}-n l_{n} \frac{\partial b_{n}}{\partial s}\right)\right] \mathrm{f}(n) \mathrm{d} n=0 . \\
& \frac{\partial \Lambda}{\partial q}=\int_{0}^{\infty}\left[-\omega_{n} \eta_{n} b_{n}+\lambda b_{n}+\lambda t n\left(\frac{\partial l_{n}^{c}}{\partial q}-b_{n} \frac{\partial l_{n}}{\partial s}\right)+\lambda\left(q-q^{P}\right)\left(\frac{\partial b_{n}^{c}}{\partial q}-b_{n} \frac{\partial b_{n}}{\partial s}\right)\right] \mathrm{f}(n) \mathrm{d} n=0 .
\end{aligned}
$$

Then, substitute definitions for the Diamond social welfare weights in eq. (5) and the compensated elasticities:

$$
\begin{aligned}
& \int_{0}^{\infty}\left[\left(1-g_{n}^{*}\right) n l_{n}+\frac{t}{(1-t)} \varepsilon_{l t} n l_{n}+\frac{\left(q-q^{P}\right)}{(1+q)} \frac{(1+q) b_{n}}{(1-t) n l_{n}} \varepsilon_{b t} n l_{n}\right] \mathrm{f}(n) \mathrm{d} n=0 . \\
& \int_{0}^{\infty}\left[\left(1-g_{n}^{*}\right) b_{n}+\frac{t}{(1-t)} \frac{(1-t)}{(1+q)} \varepsilon_{l q} n l_{n}+\frac{\left(q-q^{P}\right)}{(1+q)} \frac{b_{n}}{n l_{n}} \varepsilon_{b q} n l_{n}\right] \mathrm{f}(n) \mathrm{d} n=0 .
\end{aligned}
$$

Finally, use the definitions for the distributional characteristics $\xi_{l}$ and $\xi_{b}$ in eqs. (6a) and (6b), and use the expenditure quote $\beta_{n} \equiv \frac{(1+q) b_{n}}{(1-t) n l_{n}}$ to find the results stated in Proposition 1 .

\section{Appendix B: Examples of Gorman Polar Form Preferences}

Quasi-linear preferences: The sub-utility function for this case is $\mathrm{h}\left(c_{n}, b_{n}\right)=c_{n}+\mathrm{k}\left(b_{n}\right), \mathrm{k}^{\prime}>0, \mathrm{k}^{\prime \prime}<0$. Maximising utility subject to the private budget constraint $c_{n}+(1+q) b_{n}=m_{n}$ yields the first-order condition $\mathrm{k}^{\prime}\left(b_{n}\right)=1+q$, so demand for polluting goods is $b_{n}=\kappa(q)$ with $\kappa^{\prime}(q)=1 / \mathrm{k}^{\prime \prime}\left(b_{n}\right)$. Demand for clean goods follows residually from the private budget constraint: $c_{n}=m_{n}-(1+q) \kappa(q)$. Hence, the indirect utility function belongs to the class of Gorman polar preferences as $v\left(q, m_{n}\right)=\left(m_{n}-\varphi(q)\right) / \mathrm{p}(q)$ $=m_{n}-(1+q) \kappa(q)+\mathrm{k}(\kappa(q))$ with $\mathrm{p}(q)=1$ and $\varphi(q)=(1+q) \kappa(1+q)-\mathrm{k}(\kappa(1+q))$. This is a special case of the demand for polluting dirty goods in eq. (12) with $\alpha(q) \equiv(1+q) \kappa(1+q)$ and $\phi(q)=0$.

Standard Stone-Geary preferences: The sub-utility function for this case is 
$\mathrm{h}\left(c_{n}, b_{n}-\bar{b}\right)=\left(c_{n} /(1-a)\right)^{1-a}\left(\left(b_{n}-\bar{b}\right) / a\right)^{a}$ with $0<a<1$ and $\bar{b}>0$. Maximising utility subject to the private budget constraint gives the first-order condition $\left(\left(b_{n}-\bar{b}\right) / a\right)^{a-1}=(1+q)\left(c_{n} /(1-a)\right)^{-a}$. The demand functions for polluting and for clean goods are: $b_{n}=(1-a) \bar{b}+a m_{n} /(1+q)$ and $c_{n}=(1-a)\left(m_{n}-(1+q) \bar{b}\right)$. Upon substitution into the utility function, the Gorman polar form indirect utility function is obtained: $\mathrm{v}\left(q, m_{n}\right)=\left(m_{n}-\varphi(q)\right) / \mathrm{p}(q)=(1+q)^{-a}\left(m_{n}-(1+q) \bar{b}\right)$, so that $\mathrm{p}(q)=(1+q)^{a}$ and $\varphi(q)=(1+q) \bar{b}$. This yields a special case of the demand function in eq. (12) with $\phi(q)=a$ and $\alpha(q) \equiv(1+q)(1-a) \bar{b}$. Using $m_{n}=(1+q)^{a} h_{n}+(1+q) \bar{b}$, the compensated demand for polluting goods follows as $b_{n}=\bar{b}+a(1+q)^{a-1} h_{n}$.

Generalised Stone-Geary preferences: The sub-utility function for this case is $\mathrm{h}\left(c_{n}, b_{n}-\bar{b}\right)=$ $\left[(1-a) c_{n}^{(\sigma-1) / \sigma}+a\left(b_{n}-\bar{b}\right)^{(\sigma-1) / \sigma}\right]^{\sigma /(\sigma-1)}$ with $0<a<1$ and $\sigma>0$. Maximising utility subject to the budget constraint $c_{n}+(1+q) b_{n}=m_{n}$ gives the optimality condition $b_{n}-\bar{b}=((1+q)(1-a) / a)^{-\sigma} c_{n}$. Solving this together with the budget constraint gives the Marshallian demand functions:

$$
\begin{aligned}
& b_{n}=\frac{m_{n} /(1+q)}{1+(1+q)^{\sigma-1}((1-a) / a)^{\sigma}}+\frac{\bar{b}}{1+(1+q)^{1-\sigma}(a /(1-a))^{\sigma}}, \\
& c_{n}=\frac{m_{n}}{1+(1+q)^{1-\sigma}(a /(1-a))^{\sigma}}-\frac{(1+q) \bar{b}}{1+(1+q)^{1-\sigma}(a /(1-a))^{\sigma}} .
\end{aligned}
$$

Substituting eq. (B1) and eq. (B2) into the utility function, one finds the Gorman polar form indirect utility function $v\left(q, m_{n}\right)=\left(m_{n}-\varphi(q)\right) / \mathrm{p}(q)=(1-a)^{\sigma /(\sigma-1)}\left(1+(1+q)^{1-\sigma}(a /(1-a))^{\sigma}\right)^{1 /(\sigma-1)}\left(m_{n}-(1+q) \bar{b}\right)$ with

$$
\mathrm{p}(q)=(1-a)^{\sigma /(1-\sigma)}\left(1+(1+q)^{1-\sigma}(a /(1-a))^{\sigma}\right)^{1 /(1-\sigma)} \text { and } \varphi(q)=(1+q) \bar{b} .
$$

Demand for polluting goods is thus given by eq. (12) with

$$
\phi(q)=\left(1+(1+q)^{\sigma-1}((1-a) / a)^{\sigma}\right)^{-1} \text { and } \alpha(q)=\left(1+(1+q)^{1-\sigma}(a /(1-a))^{\sigma}\right)^{-1}(1+q) \bar{b} .
$$

\section{Appendix C: Proof of Proposition 2}

The proof requires three steps. First, if preferences are weakly separable and sub-utility belongs to the class of Gorman polar preferences the demand for dirty commodities features linear Engel curves. Second, we derive the elasticities of labour supply with respect to income and the optimal corrective pollution tax for this class of utility functions. Third, with this information, we can solve the first-order conditions to prove the proposition. 


\section{C.1 Gorman polar preferences and linear Engel curves}

Utility is $\mathrm{u}\left(\mathrm{h}\left(c_{n}, b_{n}\right), 1-l_{n}\right)-\mathrm{D}(b, n)$, where sub-utility $\mathrm{h}\left(c_{n}, b_{n}\right)$ belongs to the class of Gorman polar utility functions. The household budget constraint is given by $(1-t) n l_{n}+s=c_{n}+(1+q) b_{n} \equiv m_{n}$. We solve this problem in two stages using so-called conditional demand functions (Mirrlees, 1976; Jacobs and Boadway, 2014). In the first stage, individuals optimally choose clean and dirty consumption to maximize utility $u(\cdot)$ for a given level of labour supply $l_{n}$ subject to $c_{n}+(1+q) b_{n} \equiv m_{n}$. Labour supply will be determined in the second stage. This gives the following first-order condition:

$$
h_{b} / h_{c}=1+q .
$$

The first-order condition, joint with the budget constraint, yield the conditional demand functions for clean and dirty goods, which are functions of the pollution tax and net income: $c_{n} \equiv c^{c}\left(q, m_{n}\right)$, $b_{n} \equiv b^{c}\left(q, m_{n}\right)$. Due to the weak separability of $u(\cdot)$, the conditional demand functions are independent from labour supply (Jacobs and Boadway, 2014). These conditional demand functions then give a conditional indirect sub-utility function, which is a function of the pollution tax $q$ and net income $m_{n}$ only: $v\left(q, m_{n}\right) \equiv \mathrm{h}\left(c^{c}\left(q, m_{n}\right), b^{c}\left(q, m_{n}\right)\right)$. Moreover, from Definition 1 follows that the conditional indirect utility function is given by:

$$
h_{n}=v\left(q, m_{n}\right)=\frac{m_{n}-\phi(q)}{\mathrm{p}(q)}=\frac{(1-t) n l_{n}+s-\phi(q)}{\mathrm{p}(q)} .
$$

In the second stage, individuals thus maximise utility $u\left(\left((1-t) n l_{n}+s-\phi(q)\right) / \mathrm{p}(q), l_{n}\right)$ by optimally choosing labour supply $l_{n}$ subject to $(1-t) n l_{n}+s=m_{n}$. This gives the first-order condition:

$$
\frac{-u_{l}}{u_{h}}=\frac{(1-t) n}{\mathrm{p}(q)}
$$

\section{C.2 Compensated elasticities with Gorman polar preferences}

To find the compensated elasticities with respect to the policy instruments, we log-linearise the first-order conditions in eq. (C1) and eq. (C3) and the utility function $u(\cdot)$ around an initial equilibrium, while

keeping total utility constant. A tilde designates a relative change, e.g. $\tilde{l}_{n} \equiv \mathrm{d} l_{n} / l_{n}$, except for the relative changes in the tax rates, which are denoted $\tilde{t} \equiv \mathrm{d} t /(1-t)$ and $\tilde{q} \equiv \mathrm{d} q /(1+q)$.

Log-linearising the sub-utility function $h(\cdot)$ gives:

$$
\tilde{h}_{n}=\gamma_{c} \tilde{c}_{n}+\gamma_{b} \tilde{b}_{n}, \quad \gamma_{c} \equiv \frac{h_{c} c_{n}}{h_{n}}, \quad \gamma_{b} \equiv \frac{h_{b} b_{n}}{h_{n}}
$$


Next, log-linearising the first-order condition for consumption in eq. (C1) gives:

$$
\delta^{b} \tilde{b}_{n}=\delta^{c} \tilde{c}_{n}-\tilde{q}, \quad \delta^{c} \equiv-\left(\frac{h_{c c} c_{n}}{h_{c}}-\frac{h_{b c} c_{n}}{h_{b}}\right)>0, \quad \delta^{b} \equiv-\left(\frac{h_{b b} b_{n}}{h_{b}}-\frac{h_{c b} b_{n}}{h_{c}}\right)>0 .
$$

Log-linearising the first-order condition for labour supply in eq. (C3) yields:

$$
\tilde{l}_{n}=\frac{\varepsilon_{n}}{\zeta_{n}} \tilde{h}_{n}-\varepsilon_{n} \tilde{t}-\varepsilon_{n} \phi(q) \tilde{q}
$$

where $\varepsilon_{n} \equiv\left(u_{l l} l_{n} / u_{l}-u_{h l} l_{n} / u_{h}\right)^{-1}$ is the Frisch elasticity of labour supply, $\zeta_{n} \equiv\left(u_{h h} h_{n} / u_{h}-u_{l h} h_{n} / u_{l}\right)^{-1}$ captures income effects in labour supply, and from Definition 1 follows that $\phi(q) \equiv \mathrm{p}^{\prime}(q)(1+q) / \mathrm{p}(q)$ with Gorman polar utility.

Log-linearising utility $u\left(h_{n}, l_{n}\right)$ while keeping utility fixed - note that environmental quality $D(\cdot)$ is given for each individual - gives:

$$
u_{h} h_{n} \tilde{h}_{n}+u_{l} l_{n} \tilde{l}_{n}=0
$$

Substituting the first-order condition for labour supply from eq. (C3) in eq. (C7) yields:

$$
\tilde{h}_{n}=\frac{(1-t) n l_{n}}{\mathrm{p}(q) h_{n}} \tilde{l}_{n}=\frac{(1-t) n l_{n}}{\left((1-t) n l_{n}+s-\phi(q)\right)} \tilde{l}_{n}=\theta_{n} \tilde{l}_{n}, \quad \theta_{n} \equiv \frac{(1-t) n l_{n}}{(1-t) n l_{n}+s-\phi(q)} .
$$

Solving the system of equations in eqs. (C4), (C5), (C6), (C8) for the relative changes in $\tilde{c}_{n}, \tilde{b}_{n}, \tilde{l}_{n}$, and $\tilde{h}_{n}$ gives:

$$
\begin{aligned}
& \tilde{c}_{n}=-\frac{\delta^{b}}{\delta^{c} \gamma_{b}+\delta^{b} \gamma_{c}} \theta_{n}\left(\frac{\tilde{t}+\phi(q) \tilde{q}}{\frac{1}{\varepsilon_{n}}-\frac{\theta_{n}}{\zeta_{n}}}\right)+\frac{\gamma_{b}}{\delta^{c} \gamma_{b}+\delta^{b} \gamma_{c}} \tilde{q}, \\
& \tilde{b}_{n}=-\frac{\delta^{c}}{\delta^{c} \gamma_{b}+\delta^{b} \gamma_{c}} \theta_{n}\left(\frac{\tilde{t}+\phi(q) \tilde{q}}{\frac{1}{\varepsilon_{n}}-\frac{\theta_{n}}{\zeta_{n}}}\right)-\frac{\gamma_{c}}{\delta^{c} \gamma_{b}+\delta^{b} \gamma_{c}} \tilde{q}, \\
& \tilde{l}_{n}=-\frac{\tilde{t}+\phi(q) \tilde{q}}{\frac{1}{\varepsilon_{n}}-\frac{\theta_{n}}{\zeta_{n}}}, \tilde{h}_{n}=-\theta_{n}\left(\frac{\tilde{t}+\phi(q) \tilde{q}}{\frac{1}{\varepsilon_{n}}-\frac{\theta_{n}}{\zeta_{n}}}\right) .
\end{aligned}
$$

From eq. (C9) follow the compensated elasticities of labour supply and demand for polluting goods with respect to the tax instruments:

$$
\varepsilon_{l t} \equiv \frac{\partial l_{n}^{c}}{\partial t} \frac{1-t}{l_{n}}=-\frac{1}{\frac{1}{\varepsilon_{n}}-\frac{\theta_{n}}{\zeta_{n}}}, \quad \varepsilon_{l q} \equiv \frac{\partial l_{n}^{c}}{\partial q} \frac{1+q}{l_{n}}=-\frac{\phi(q)}{\frac{1}{\varepsilon_{n}}-\frac{\theta_{n}}{\zeta_{n}}} .
$$

(C11) $\varepsilon_{b t} \equiv \frac{\partial b_{n}^{c}}{\partial t} \frac{1-t}{b_{n}}=-\frac{\delta^{c} \theta_{n}}{\left(\delta^{c} \gamma_{b}+\delta^{b} \gamma_{c}\right)\left(\frac{1}{\varepsilon_{n}}-\frac{\theta_{n}}{\zeta_{n}}\right)}, \quad \varepsilon_{b q} \equiv \frac{\partial b_{n}^{c}}{\partial q} \frac{1+q}{b_{n}}=-\frac{\delta^{c} \theta_{n} \phi(q)}{\left(\delta^{c} \gamma_{b}+\delta^{b} \gamma_{c}\right)\left(\frac{1}{\varepsilon_{n}}-\frac{\theta_{n}}{\zeta_{n}}\right)}-\frac{\gamma_{c}}{\delta^{c} \gamma_{b}+\delta^{b} \gamma_{c}}$.

Consequently, we derive $\varepsilon_{l q}=\phi(q) \varepsilon_{l t}$ and $\phi(q) \varepsilon_{b t}-\varepsilon_{b q}=\gamma_{c} /\left(\delta^{c} \gamma_{b}+\delta^{b} \gamma_{c}\right)>0$. Moreover, in the absence 
of income effects, we have $\zeta_{n}=\infty$, so that $\varepsilon_{l t}=-\varepsilon_{n}, \varepsilon_{l q}=-\phi(q) \varepsilon_{n}$.

\section{C.3 Solving for the policy optimum with Gorman polar preferences}

Substituting eq. (C3) for Gorman polar form preferences into eq. (A11) yields:

$$
\int_{0}^{\infty}\left[\left(1-g_{n}^{*}\right)\left(\frac{\alpha(q)}{(1+q)}+\frac{\phi(q)}{(1+q)}\left((1-t) n l_{n}+s\right)\right)+\frac{t}{(1-t)} \frac{(1-t)}{(1+q)} n l_{n} \varepsilon_{l q}+\frac{\left(q-q^{P}\right)}{(1+q)} \frac{b_{n}}{n l_{n}} n l_{n} \varepsilon_{b q}\right] \mathrm{f}(n) \mathrm{d} n=0 .
$$

Since $\alpha(q) /(1+q)+\phi(q) s /(1+q)$ does not depend on $n$ we have, using the first-order condition for $s$ in eq. (A7):

$$
\int_{0}^{\infty}\left[\left(1-g_{n}^{*}\right)\left(\frac{\alpha(q)+\phi(q) s}{(1+q)}\right)\right] \mathrm{f}(n) \mathrm{d} n=0
$$

Hence, we can write eq. (C18) as:

$$
\int_{0}^{\infty}\left[\left(1-g_{n}^{*}\right) n l_{n}+\frac{t}{(1-t)} \frac{\varepsilon_{l q}}{\phi(q)} n l_{n}+\frac{\left(q-q^{P}\right)}{(1+q)} \frac{\beta_{n} \varepsilon_{b q}}{\phi(q)} n l_{n}\right] \mathrm{f}(n) \mathrm{d} n=0
$$

Subtract (A10) from eq. (C19) to find:

$$
\int_{0}^{\infty}\left[\frac{t}{(1-t)}\left(\frac{\varepsilon_{l q}}{\phi(q)}-\varepsilon_{l t}\right) n l_{n}+\frac{\left(q-q^{P}\right)}{(1+q)} \beta_{n}\left(\frac{\varepsilon_{b q}}{\phi(q)}-\varepsilon_{b t}\right) n l_{n}\right] \mathrm{f}(n) \mathrm{d} n=0
$$

For the general class of weakly separable utility functions with Gorman polar preferences we have shown in eq. (C10) that $\varepsilon_{l q} / \phi(q)=\varepsilon_{l t}$. Moreover, we derived in eq. (C11) that $\phi(q) \varepsilon_{b t}>\varepsilon_{b q}$. Consequently, the first term in brackets is zero and the second term is negative. Hence, optimal policy entails Pigouvian corrective taxes: $q=q^{P}$. Substitution of $q=q^{P}$ in Proposition 1 yields Proposition 2.

\section{Appendix D: Proof of Corollary 1}

If utility is $\mathrm{u}\left(\mathrm{h}\left(c_{n}, b_{n}\right), 1-l_{n}\right)=\mathrm{h}\left(c_{n}, b_{n}\right)-l_{n}^{1+1 / \vartheta} /(1+1 / \vartheta)$ and $\mathrm{h}\left(c_{n}, b_{n}\right)$ is of the Gorman (1961) polar form, private marginal utility of income $\eta_{n}$ is constant. Consequently, labour supply is given by $l_{n}=[(1-t) n / \mathrm{p}(q)]^{\vartheta}$, the uncompensated wage elasticity of labour supply with respect to the tax rate equals $\vartheta$, and income effects in labour supply are absent. Using quasi-linearity of the utility function (i.e., $\left.u_{l h}=u_{h h}=0\right)$, the compensated wage elasticity equals the Frisch elasticity $\varepsilon_{n}=\left(u_{l l} l_{n} / u_{l}\right)^{-1}=\vartheta$ and the income-effect term is $\zeta_{n}=\infty$. Thus, eq. (C10) gives $\varepsilon_{l t}=-\vartheta$ and $\varepsilon_{l q}=-\vartheta \phi(q)$. The optimal income tax from eq. (14) thus boils down to $t /(1-t)=\xi_{l} / \vartheta$. The Diamond social welfare weights are equal to the standard social welfare weights if income effects in labour supply are absent and pollution taxes are 
Pigouvian (i.e., $\partial l_{n} / \partial s=0$ and $q=q^{P}$ ), so that $g_{n}^{*}=g_{n}=\omega_{n} \eta_{n} / \lambda=\omega_{n} \mathrm{p}(q) / \lambda$. Substitution of this in eq. (15) yields $\mathrm{p}(q) \int_{0}^{\infty} \omega_{n} \mathrm{f}(n) \mathrm{d} n=\mathrm{p}(q)=\lambda$, since we have normalised the average Pareto weights to 1 . If environmental damages are independent from ability, $\mathrm{D}_{b}(b, n)=\mathrm{D}^{\prime}(b)$, eq. (13) boils down to $q=q^{P} \equiv \int_{0}^{\infty} g_{n} \mathrm{D}_{b}(b, n) / \eta_{n} \mathrm{f}(n) \mathrm{d} n=\left(\mathrm{D}^{\prime}(b) / \lambda\right) \int_{0}^{\infty} \omega_{n} \mathrm{f}(n) \mathrm{d} n=\mathrm{D}^{\prime}(b) / \mathrm{p}(q)$. Note that if the government is utilitarian, i.e., $\omega_{n}=1$ for all $n$, then we have that the social welfare weights are all constant and equal to: $g_{n}^{*}=p(q) / \lambda$. Hence, the Feldstein characteristic of labour income is zero $\left(\xi_{l}=0\right)$ and optimal income taxes are zero, too $(t=0)$.

\section{Appendix E: Proof of Proposition 3}

We consider the following marginal tax reform. We raise the pollution $\operatorname{tax} q$ and the transfer $s$, and we lower the income tax $t$ so that net income of each household remains constant. We thus consider a tax reform so that $\mathrm{d} s=n l_{n} \mathrm{~d} t+b_{n} \mathrm{~d} q$. Substituting demand for polluting goods in eq. (12) into this eq. gives:

(E1) $\quad \mathrm{d} s=\left(\frac{\phi(q)(1-t)}{1+q}+\frac{\mathrm{d} t}{\mathrm{~d} q}\right) n l_{n} \mathrm{~d} q+\left(\frac{\alpha(q)+\phi(q) s}{1+q}\right) \mathrm{d} q$.

Suppose, then, that we implement the following tax reform, which satisfies eq. (E1):

(E2) $\quad \mathrm{d} s=\left(\frac{\alpha(q)+\phi(q) s}{1+q}\right) \mathrm{d} q$ and $\mathrm{d} t=-\frac{\phi(q)(1-t)}{1+q} \mathrm{~d} q$.

This tax reform is feasible for all individuals $n$, since the marginal propensity to consume polluting goods out of net labour income $\phi(q)$ and the intercept of the Engel curve $\alpha(q)$ are the same for everyone. This tax reform leaves non-environmental utility $\mathrm{u}(\cdot)$ and net incomes unchanged. Hence, all behavioural responses are compensated changes and there are no income effects. The only effect of the tax reform on private utility is via the change in environmental welfare.

Totally differentiating indirect utility yields (using Roy's identity): $\mathrm{d} v_{n}=-\eta n l_{n} \mathrm{~d} t-\eta b_{n} \mathrm{~d} q+\eta \mathrm{d} s-D_{b} \mathrm{~d} b=-D_{b} \mathrm{~d} b$. Totally differentiate total demand for polluting goods to find:

$$
\mathrm{d} b=\int_{0}^{\infty} \mathrm{d} b_{n} \mathrm{f}(n) \mathrm{d} n=\int_{0}^{\infty}\left(\frac{\partial b_{n}}{\partial t}+\frac{\partial b_{n}}{\partial q} \frac{\mathrm{d} q}{\mathrm{~d} t}\right) \mathrm{f}(n) \mathrm{d} n .
$$

What is the effect of such a tax reform on social welfare? There are two effects: first environmental welfare changes (non-environmental welfare is unaffected) and the government budget changes when the tax system is not optimised. We can use the compensated elasticities here, since non-environmental utility 
does not change in the reform. The effect on environmental welfare is the sum of the utility changes over the entire population - deflated by the marginal utility of public resources $\lambda$ :

$$
\frac{\mathrm{d} \Lambda}{\lambda}=\frac{1}{\lambda} \int_{0}^{\infty} \omega_{n} \mathrm{~d} v_{n} \mathrm{f}(n) \mathrm{d} n=-\int_{0}^{\infty} \omega_{n} \frac{D_{b}(\cdot)}{\lambda} \mathrm{d} b \mathrm{f}(n) \mathrm{d} n=-\int_{0}^{\infty} g_{n} \frac{\mathrm{D}_{b}(\cdot)}{\eta_{n}} \mathrm{f}(n) \mathrm{d} n \int_{0}^{\infty}\left(\frac{\partial b_{n}}{\partial t}+\frac{\partial b_{n}}{\partial q} \frac{\mathrm{d} q}{\mathrm{~d} t}\right) \mathrm{f}(n) \mathrm{d} n .
$$

Next, substitute $q^{P} \equiv \int_{0}^{\infty} g_{n} \frac{\mathrm{D}_{b}(b, n)}{\eta_{n}} \mathrm{f}(n) \mathrm{d} n$ to find:

$$
\frac{1}{\lambda} \frac{\mathrm{d} \Lambda}{\mathrm{d} t}=-q^{P} \int_{0}^{\infty}\left(\frac{b_{n}}{1-t} \frac{\partial b_{n}}{\partial t} \frac{1-t}{b_{n}}+\frac{b_{n}}{1+q} \frac{\partial b_{n}}{\partial q} \frac{1+q}{b_{n}} \frac{\mathrm{d} q}{\mathrm{~d} t}\right) \mathrm{f}(n) \mathrm{d} n
$$

Then, employ $\mathrm{d} q / \mathrm{d} t=-(1+q) /(\phi(q)(1-t))$ to find the welfare effect of a change in environmental quality:

$$
\frac{1}{\lambda} \frac{\mathrm{d} \Lambda}{\mathrm{d} t}=-\frac{q^{P}}{1+q} \int_{0}^{\infty} \beta_{n} n l_{n}\left(\varepsilon_{b t}-\frac{\varepsilon_{b q}}{\phi(q)}\right) \mathrm{f}(n) \mathrm{d} n .
$$

If $R$ denotes total tax revenues, the effects on the government budget are found by totally differentiating the government budget constraint:

$$
\frac{\mathrm{d} R}{\mathrm{~d} t}=\int_{0}^{\infty}\left[n l_{n}+\operatorname{tn} \frac{\partial l_{n}}{\partial t}+\operatorname{tn} \frac{\partial l_{n}}{\partial q} \frac{\mathrm{d} q}{\mathrm{~d} t}+b_{n} \frac{\mathrm{d} q}{\mathrm{~d} t}+q \frac{\partial b_{n}}{\partial q} \frac{\mathrm{d} q}{\mathrm{~d} t}+q \frac{\partial b_{n}}{\partial t}-\frac{\mathrm{d} s}{\mathrm{~d} t}\right] \mathrm{f}(n) \mathrm{d} n .
$$

Next, substitute the tax reform $\mathrm{d} q / \mathrm{d} t=-(1+q) /(\phi(q)(1-t))$ and $\mathrm{d} s / \mathrm{d} t=-(\alpha(q)+\phi(q) s) /(\phi(q)(1-t))$ and rearrange to get:

$$
\frac{\mathrm{d} R}{\mathrm{~d} t}=\int_{0}^{\infty} n l_{n}\left[\frac{t}{(1-t)}\left(\varepsilon_{l t}-\frac{\varepsilon_{l q}}{\phi(q)}\right)+\frac{q}{(1+q)} \beta_{n}\left(\varepsilon_{b t}-\frac{\varepsilon_{b q}}{\phi(q)}\right)\right] \mathrm{f}(n) \mathrm{d} n .
$$

The total welfare effect of the tax reform is then equal to eq. (E8) plus eq. (E6). Rewriting while using $\mathrm{d} q / \mathrm{d} t=-(1+q) /(\phi(q)(1-t))$ gives:

$$
\frac{1}{\lambda} \frac{\mathrm{d} \Lambda}{\mathrm{d} q}+\frac{\mathrm{d} R}{\mathrm{~d} q}=-\int_{0}^{\infty} b_{n}\left[\frac{t}{(1-t)} \frac{\phi(q)}{\beta_{n}}\left(\varepsilon_{l t}-\frac{\varepsilon_{l q}}{\phi(q)}\right)+\frac{\left(q-q^{P}\right)}{(1+q)}\left(\phi(q) \varepsilon_{b t}-\varepsilon_{b q}\right)\right] \mathrm{f}(n) \mathrm{d} n .
$$

Clearly, if preferences are weakly separable and belong to the Gorman polar form, we have from eq. (C10) that $\varepsilon_{l t}=\varepsilon_{l q} / \phi(q)$, hence the total effect of the tax reform on social welfare equals:

(E10) $\frac{1}{\lambda} \frac{\mathrm{d} \Lambda}{\mathrm{d} q}+\frac{\mathrm{d} R}{\mathrm{~d} q}=\int_{0}^{\infty} b_{n}\left[\frac{\left(q^{P}-q\right)}{(1+q)}\left(\phi(q) \varepsilon_{b t}-\varepsilon_{b q}\right)\right] \mathrm{f}(n) \mathrm{d} n$.

We derived in eq. (C11) that $\phi(q) \varepsilon_{b t}>\varepsilon_{b q}$. This corresponds to eq. (17) of Proposition 3. 


\section{Appendix F: Proof optimal taxation with production externalities}

The derivatives of indirect utility to the tax instruments are: $\partial v_{n} / \partial s=\eta_{n}, \partial v_{n} / \partial t=-\eta_{n} A(b) n l_{n}$, $\partial v_{n} / \partial q=-\eta_{n} b_{n}$, and $\partial v_{n} / \partial b=\eta_{n}(1-t) A^{\prime}(b) n l_{n}$. The Lagrangian $\Lambda$ for the maximisation of social welfare is modified to:

$$
\max _{\{t, q, s, b\}} \Lambda \equiv \int_{0}^{\infty} \omega_{n} \mathrm{v}(t, q, s, b, n)+\lambda\left[t A(b) n l_{n}+q b_{n}-s-R\right] \mathrm{f}(n) \mathrm{d} n+\mu\left[b-\int_{0}^{\infty} b_{n} \mathrm{f}(n) \mathrm{d} n\right] .
$$

The following necessary first-order conditions have to hold:

$$
\begin{aligned}
& \frac{\partial \Lambda}{\partial s}=\int_{0}^{\infty}\left[\omega_{n} \eta_{n}-\lambda+\lambda t A(b) n \frac{\partial l_{n}}{\partial s}+(\lambda q-\mu) \frac{\partial b_{n}}{\partial s}\right] \mathrm{f}(n) \mathrm{d} n=0, \\
& \frac{\partial \Lambda}{\partial t}=\int_{0}^{\infty}\left[-\omega_{n} \eta_{n} A(b) n l_{n}+\lambda A(b) n l_{n}+\lambda t A(b) n \frac{\partial l_{n}}{\partial t}+(\lambda q-\mu) \frac{\partial b_{n}}{\partial t}\right] \mathrm{f}(n) \mathrm{d} n=0,
\end{aligned}
$$

$$
\frac{\partial \Lambda}{\partial q}=\int_{0}^{\infty}\left[-\omega_{n} \eta_{n} b_{n}+\lambda b_{n}+\lambda t A(b) n \frac{\partial l_{n}}{\partial q}+(\lambda q-\mu) \frac{\partial b_{n}}{\partial q}\right] \mathrm{f}(n) \mathrm{d} n=0,
$$

$$
\frac{\partial \Lambda}{\partial b}=\int_{0}^{\infty}\left[\omega_{n} \eta_{n}(1-t) A^{\prime}(b) n l_{n}+\lambda t A^{\prime}(b) n l_{n}+\mu+\lambda t A(b) n \frac{\partial l_{n}}{\partial b}+(\lambda q-\mu) \frac{\partial b_{n}}{\partial b}\right] \mathrm{f}(n) \mathrm{d} n=0,
$$

where we have used Roy's identity in each line to substitute for the derivatives of indirect utility.

Using $\frac{\partial l_{n}}{\partial b}=\frac{\partial l_{n}}{\partial w} A^{\prime}(b)=-\frac{\partial l_{n}}{\partial t} \frac{1-t}{w} A^{\prime}(b), \frac{\partial b_{n}}{\partial b}=\frac{\partial b_{n}}{\partial w} A^{\prime}(b)=-\frac{\partial b_{n}}{\partial t} \frac{1-t}{w} A^{\prime}(b)$, where the second steps follow from $\frac{\partial l_{n}}{\partial w}=-\frac{\partial l_{n}}{\partial t} \frac{1-t}{w}$, and $\frac{\partial b_{n}}{\partial w}=-\frac{\partial b_{n}}{\partial t} \frac{1-t}{w}$, the first-order condition for optimal pollution $b$ in eq. (F5), can be rewritten as:

$$
\int_{0}^{\infty}\left[\omega_{n} \eta_{n} n l_{n}+\lambda \frac{t}{1-t} n l_{n}+\frac{\mu}{(1-t) A^{\prime}(b)}-\lambda t n \frac{\partial l_{n}}{\partial t}-\frac{(\lambda q-\mu)}{w} \frac{\partial b_{n}}{\partial t}\right] \mathrm{f}(n) \mathrm{d} n=0 .
$$

Next, substitute the first-order condition for $t$ in eq. (F3) to derive that the Pigouvian pollution tax is given by the sum of marginal pollution damages in production:

$$
q^{P} \equiv \frac{\mu}{\lambda}=-A^{\prime}(b) \int_{0}^{\infty} n l_{n} \mathrm{f}(n) \mathrm{d} n=-\frac{A^{\prime}(b)}{A(b)} Y .
$$

We can simplify the first-order conditions for $s, t$ and $q$, i.e., eqs. (F2), (F3) and (F4) following the same steps as in Appendix A, to replicate the optimal tax formulae of Proposition 1 with a social marginal utility of income of $g_{n}^{*} \equiv g_{n}+t A(b) n \frac{\partial l_{n}}{\partial s}+\left(q-q^{P}\right) \frac{\partial b_{n}}{\partial s}$ and an expenditure share of $\beta_{n} \equiv \frac{(1+q) b_{n}}{(1-t) A(b) n l_{n}}$. 